QL 53

. $W_{39}$ 


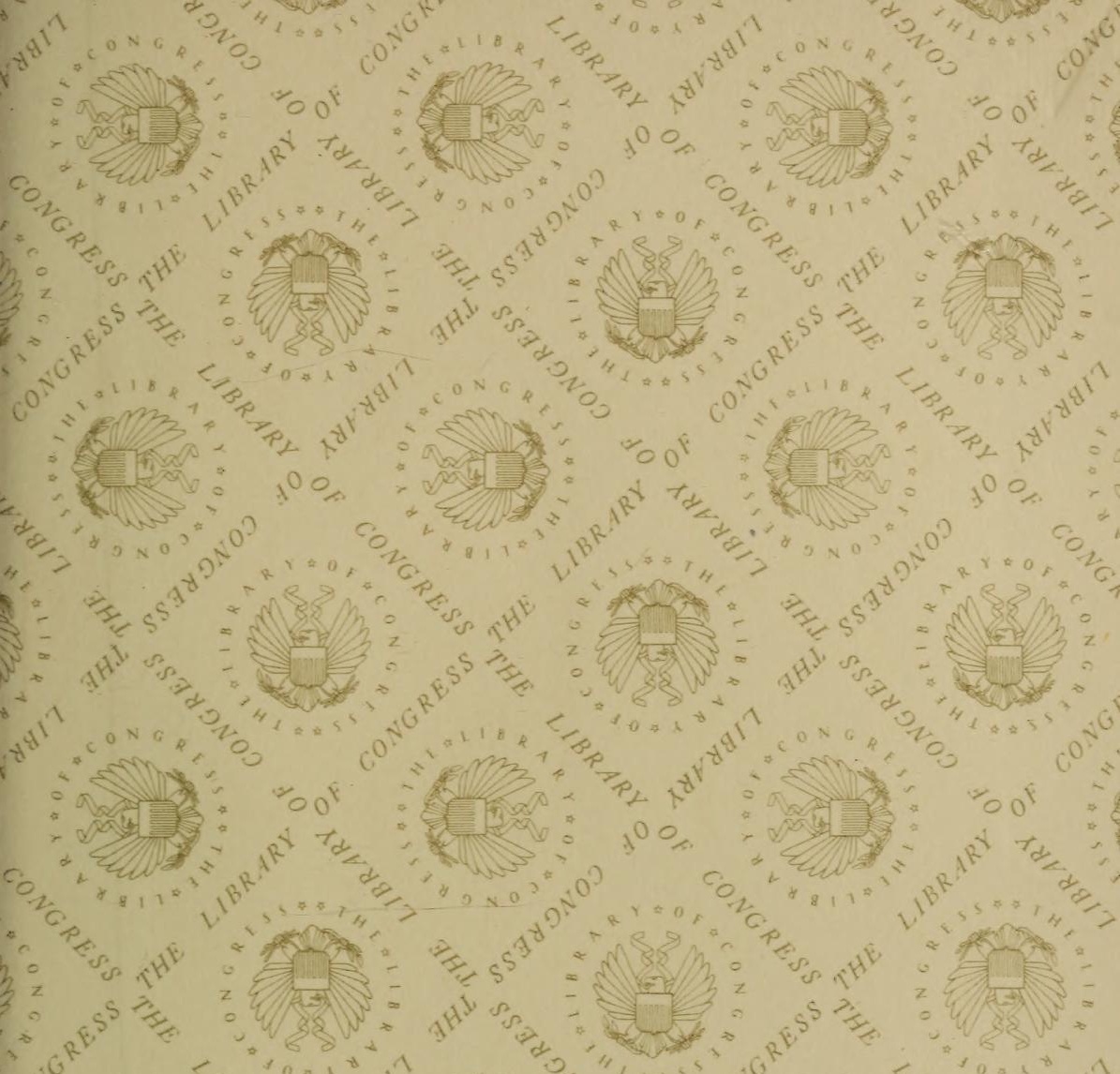

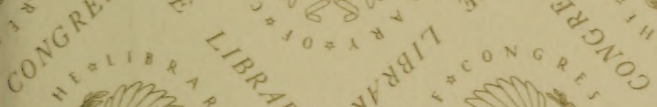

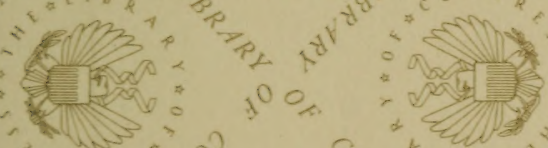

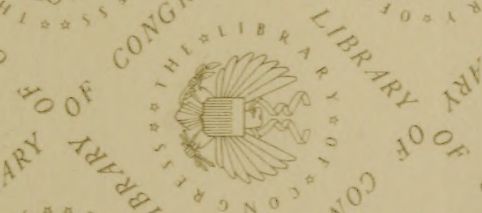

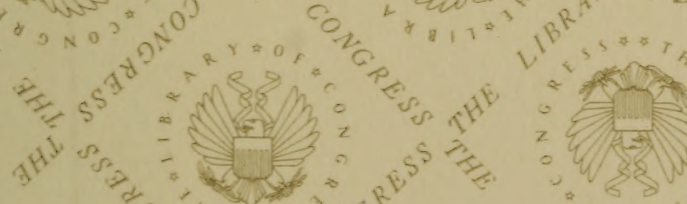
4 a

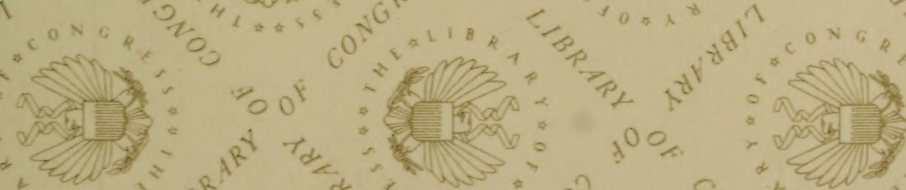

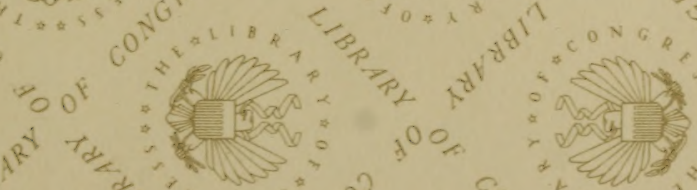




y. 


\section{A LABORATORY GUIDE FOR BEGINNERS IN ZOOLOGY}

BY

CLARENCE MOORES WEED, D.Sc.

AND

RALPH WALLACE CROSSMAN; A.B., M.Sc.

BOSTON, U.S.A.

D. C. HEATH \& CO., PUBLISHERS 


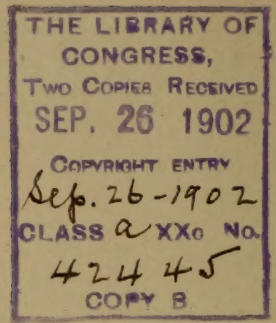

COPYRIGHT, I902,

By ClaRENCE M. WEED

AND RALPH W. CROSSMAN.

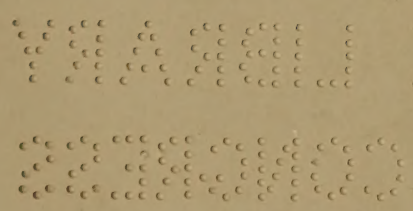

Tímpton Dresg

H. M. PLIMPTON \& CO., PRINTERS \& BINDERS,

NORWOOD, MASS., U.S.A. 


\section{PREFACE}

IT is generally conceded that a satisfactory course in zoology requires both laboratory study of animal forms and lecture or text-book presentation of the laws of animal life. The teachers most conversant with pedagogical principles also contend that the greatest educational value of the subject lies in the opportunity it gives to furnish the student with an adequate first-hand knowledge of organic evolution. To accomplish this a course in which the pupil begins with the lower forms and works gradually upward is necessary. For the pupil thus follows the development of living things, seeing how each succeeding form is an improvement over the one that went before, and getting some idea of the great laws which govern the growth and sequence of animal life.

In his study of these forms of life the pupil needs a guide which shall lead him wisely without telling him too much, and which shall stimulate him to see and to think without bewildering him with questions that he cannot answer. In this little book such an attempt is made. Since the directions were first used in my own classes some ten years ago modifications have been made every year, until in their present form I have found them thoroughly workable with average classes of beginners in zoology. 
The directions in the introductory chapter are designed to help the teacher in getting material for study; they are not intended for the pupil, although the figures should be helpful in enabling the teacher to show the class what to look for in the case of the microscopic specimens.

In the preparation of a few of the chapters valuable assistance has been rendered by Mr. Albert F. Conradi, while the drawings have been made by Mr. Robert A. Cushman. The authors are also under great obligations to Professor J. H. Gerould of Dartmouth College, who has kindly read the proof, and made many valuable suggestions for the improvement of the Guide.

C. M. W.

New HAMPSHIRE College OF Agriculture and MeChanic ARTs, DURHAM, August, IgO2. 


\section{CONTENTS}

\section{INTRODUCTION}

The Laboratory and its Equipment. . . . . . . ix

The Cultivation and Preparation of Material . . . . xi

CHAPTER

I. BRANCH PROTOZOA: The One-celled Animals I The Amœba . . . . • • • • . . . I

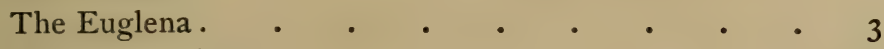

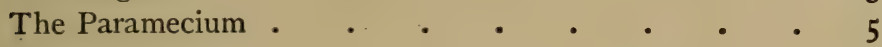

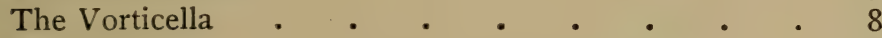

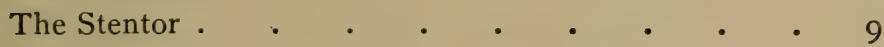

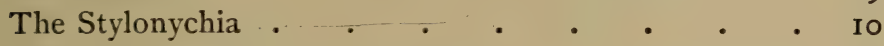

The Classification of the Protozoa . $\quad$. $\quad$. $\quad$. 12

II. BRANCH PORIFERA: THE SPONGeS • • . 15

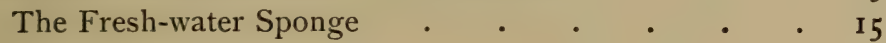

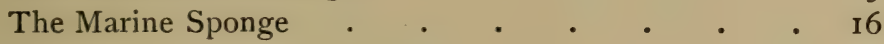

The Classification of the Porifera . . . . . 18

III. BRANCH COElEnteratA: The Hydras and Sea-

ANEMONES • • • • • • • • • • 20

The Fresh-water Hydra . . . . . . . 20

The Campanularian Hydroid . . . . 23

The Hydro-medusa . . . . . . . 26

The Tubularian Hydroid.$\quad$. $\quad$ • $\quad$ • 27

The Classification of the Cœlenterata . • . 29

IV. BRANCH TROCHELMINTHES: THE ROTIFERS AND

their Allies • • • • • • • • • • $3 \mathrm{I}$

The Rotifer, or Wheel Animalcule . . . . . 3 I

The Classification of the Rotifers and their Allies : . 33 
V. BRANCH ECHINODERMATA: THE STARFISHES AND SEA-URCHINS The Starfish . The Sea-urchin . $\quad . \quad$. $\quad . \quad$. $\quad . \quad . \quad .40$ The Sea-cucumber . $\quad . \quad$. $\quad . \quad$. $\quad$. $\quad$. 42 The Classification of the Echinodermata $\quad$. $\quad$. 44

VI. BRANCH ANNULATA: The TRUe WormS . . 46 The Earthworm . . . . . . . . . 46 The Marine Annelid . . . . . . . . 49 The Classification of the Annulata . . . $\quad 52$

VII. BRANCH ARTHROPODA: ThE ANIMALS WITH JOINTED LEGS.

The Wood-louse, or Sow-bug . . . . . $\quad$. 53

The Lobster, or Crayfish ․ $\quad$. $\quad . \quad$. $\quad$. 54 The Crab . $\quad . \quad$. $\quad . \quad$. $\quad . \quad$. 60

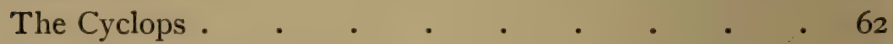

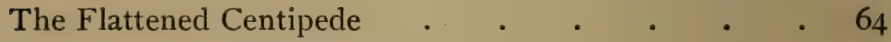
The Locust, or Grasshopper . . . . . : 65 The Dragon-fly . . . . . . . . . 68

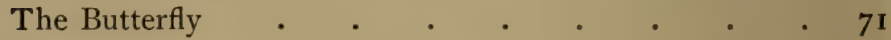

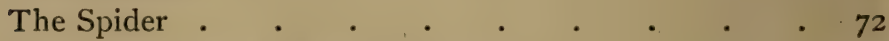
The Classification of the Arthropoda . . . $\quad$. 74

ViII. BRANCH MOLLUSCA: The Oyster, Clams, and SNAILS

The Clam

The Snail . . . . . . . . . . 82

The Squid . $\quad . \quad . \quad . \quad . \quad . \quad . \quad . \quad . \quad 83$

The Classification of the Mollusca . • . . $\quad 85$

IX. BRANCH CHORDATA: The Vertebrates • . 87 The Perch . . . . . . . . . 87

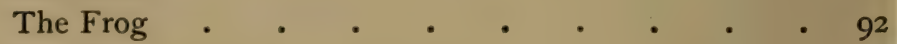

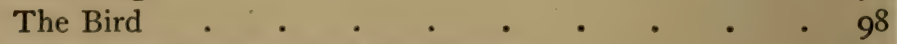
The Classification of the Vertebrates . . . . 102 


\section{INTRODUCTION}

THE LABORATORY: ITS EQUIPMENT AND THE PREPARATION OF MATERIAL 


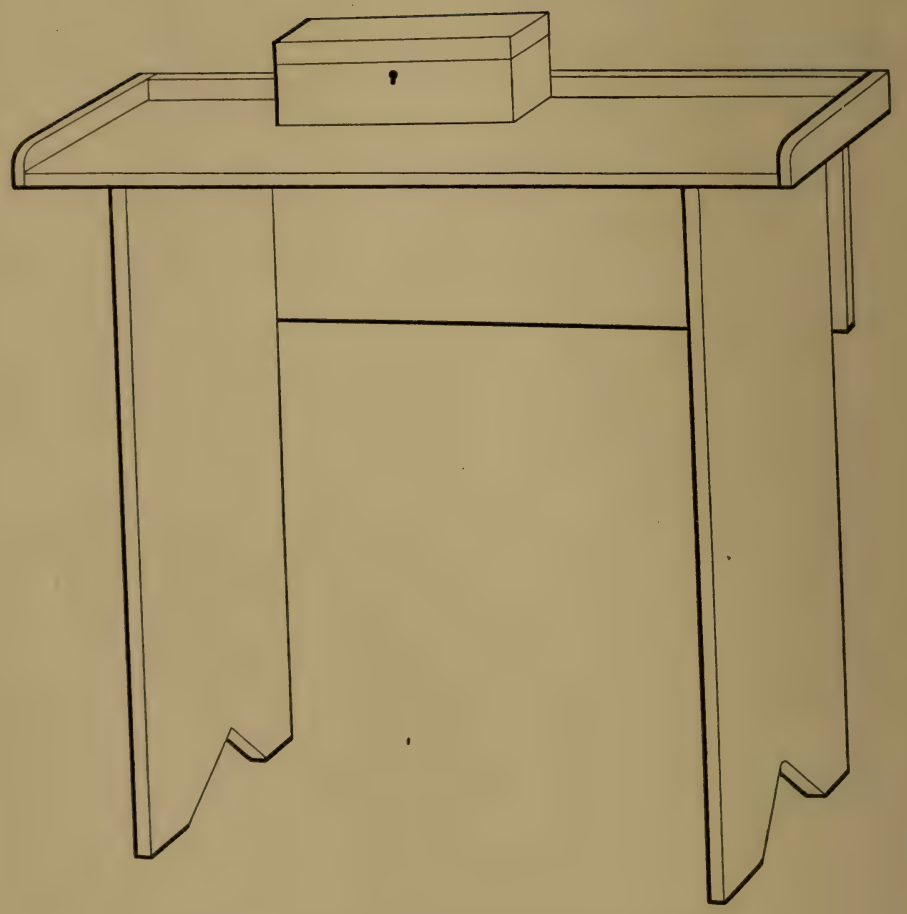

FIG. I. A Movable Laboratory Table. 


\section{INTRODUCTION}

\section{THE LABORATORY AND ITS EQUIPMENT}

THE zoological laboratory should be a well-lighted room, with sufficient space for each student to work comfortably. When possible it is better not to have direct sunshine through the windows during the hours of work.

The laboratory must be fitted with some form of desks or tables, at which the student can work with ease. When good-sized laboratory tables were not available, I have found individual tables, like the one shown in Figure I, fairly satisfactory, especially for rooms which cannot be permanently fitted up with more expensive desks. Such tables have many advantages. On the one hand they are readily movable, so that the space can be divided according to the size of the class, no more desks being kept in the room than are needed for use ; they are made of different heights, so that they can be adapted to individual students ; they may be shifted about as the conditions' of the light may demand; they enable the teacher to insist that each student shall work alone, without assistance from others; and they prevent the joggling of the microscope of others when a pupil uses the eraser, or is restless at his desk. On the other hand, they are liable not to rest squarely upon the floor if it is not carefully laid, or has become worn through use, and in the form I have used there is no drawer in which to keep appliances. The addition of a drawer would render them more useful. 
The desk illustrated in the figure is twenty-seven inches high, and is made of pine boards, one inch thick; the top board is eighteen inches wide by thirty-two inches long.

Whenever possible, each pupil should be provided with a compound microscope, magnifying to about five hundred diameters. There are, of course, many forms of microscopes to choose from. In selecting them, the aim must generally be to get the best instrument for the least money. In my own laboratory I have used with satisfaction the Leitz Stand No. 2, with objectives 3 and 7 and eye-pieces I and 3 , an outfit costing \$I 7 when imported duty free. The stand has no rack and pinion adjustment, but it serves its purpose admirably. Similar simple forms of American makers will probably prove equally satisfactory, and there should be no difficulty in getting a microscope suitable for work in elementary zoology at the price named.

If the pupils have not before used the compound microscope, a preliminary exercise should be given before the work in zoology is taken up. An excellent guide to such an exercise will be found in Dr. Charles H. Clark's " Practical Methods in Microscopy," in which there are also given plain directions for preparing the few staining solutions called for in this manual.

A few glass slides, cover glasses, and two or three watch glasses are necessary for each desk. A pair of small, sharp-pointed scissors, forceps, and scalpel are also needed, as well as a shallow tray or dish for the dissections that are to be done under water. Shallow pans of granite-ware, with sheet cork embedded on the bottom in plaster of Paris, serve very well; but the wax-lined dissecting trays now on the market are the best of all.

The teacher should be provided with the admirable "Text-book of Zoology," by Parker and Haswell, the 
classification of which is followed in this guide, and should have for reference as many other books on the subject as possible. Among the more important of these, mention may be made of the following:-

Thomson's "Study of Animal Life."

"The Riverside Natural History."

"The Cambridge Natural History."

Claus's "Text-book of Zoology."

Lang's "Text-book of Comparative Anatomy."

McMurrich's “Invertebrate Morphology.”

Packard's "Text-book of Entomology."

Comstock's "Manual for the Study of Insects."

Parker's "Elementary Biology."

Hertwig's "General Principles of Zoology.”

Jordan and Kellogg's " Animal Life.”

Jordan and Heath's " Animal Forms."

It is very desirable that some book should be studied by the class as a text-book to supplement the knowledge obtained through the laboratory study.

\section{THE CULTIVATION AND PREPARATION OF MATERIAL}

Perhaps the greatest difficulty that confronts the inexperienced teacher of zoology is found in obtaining the material to be studied, in sufficient quantity and in good condition for class use. Success with the laboratory method of instruction in biological subjects renders it imperative that the organism selected should be on hand in the right conditions and at the right time. To accomplish this, however, is no light task. The subjects are to be taken up in a certain definite order and at certain definite times, and the specimens studied, to be of the most value, 
must show the different phases of their growth. In those cases where the organisms are sufficiently abundant in the outer world to be available in quantity, it seldom happens that they present the desired phases of their existence at the time when it is necessary to study them. In a large proportion of cases they are not sufficiently abundant out of doors to be readily obtained in the needed quantity.

Fortunately these difficulties may to a great extent be overcome by indoor culture of the organisms required. For several years I have been experimenting with such cultures, and in the following pages I have summarized such of the results as seem likely to be of assistance to those who use this book. The apparatus required for such cultures is simple and easily obtained. For the aquarium cultures, glass dishes and jars of almost any size and shape may be used. Perhaps no one general form is so cheap and satisfactory as the special aquarium jars recently placed upon the market by the dealers in microscopes and laboratory supplies. These are of convenient size and shape for cultures of many kinds, and a dozen or more of them are of the greatest value to the work of any zoological laboratory. Glass covers for them should be purchased. But in case these aquarium jars are not at hand, wide-mouthed museum jars or beakers, or even fruit cans and jelly glasses, will serve the purpose, very well.

\section{THE AMGEBA}

Amœbæ may be found in the waters of ponds and ditches, but one is more certain to have them when wanted by providing aquarium cultures. Almost any of the small aquaria described in these pages are likely to furnish good amœbæ, if one examines the sediment that gathers on the sides or bottom of the vessel. I have often obtained 

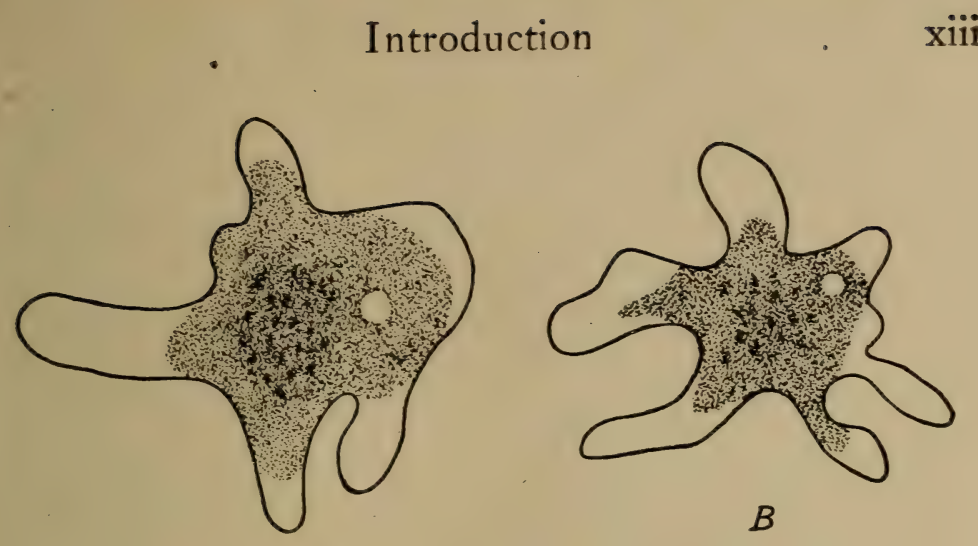

\section{A}
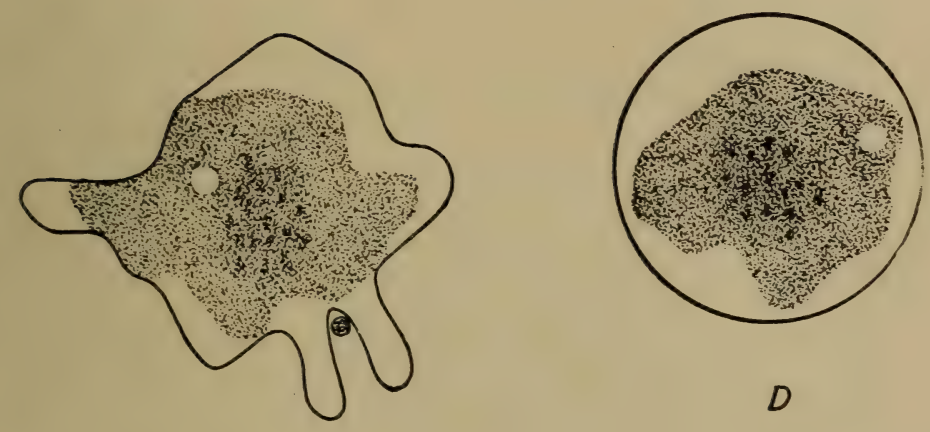

C

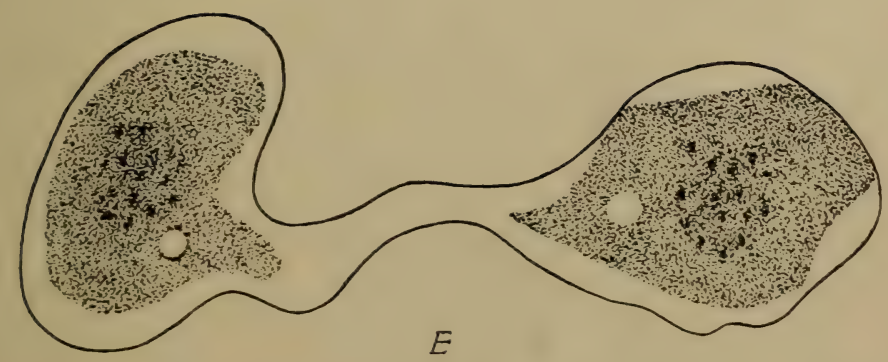

THE AмбвB: $A, B, C$, shapes assumed with pseudopods extended; $D$, shape when encysted; $E$, shape when dividing. Magnified. 
an abundance of fine specimens by placing small pieces of bark from trees or pond sides in small aquaria. After the culture vessel has stood in a warm room two or three weeks, remove the piece of bark from the water, and with a fine brush scrape off on to a glass slide some of the liquid adhering to it. Frequently there will be dozens of amœbæ in a single mount. By floating a cover glass on the surface of the water of a jar containing amœbæ and kept in a diffuse light for a day or two, specimens may be obtained free from sediment.

In studying the amœba, one should not be content with small amœboid creatures having no contractile vacuole. The large typical specimens showing contractile vacuole and the nucleus may be obtained by a series of such aquarium cultures as are here described. If the aquarium is in a north window, it is well to put it in a warm sunny situation a few hours before studying, as the amœbæ thus tecome much more active, and are of greater value for study. With such specimens the vacuole may be seen to contract, the distinction between the endosarc and the ectosarc may be made out, the ingestion and egestion of food particles may be observed, and my latest classes in zoology saw the whole process of reproduction by fission.

The nucleus may be brought out in the amœba by staining with iodine, methyl green, or blue, and with various other reagents.

If the water in a culture jar in which amœbæ are abundant is allowed slowly to evaporate, one will often be able to get good examples to illustrate the process of encystment. If the jar is finally allowed to become dry and is then stored away, the culture may be started again months later by adding water - a method first suggested, I believe, by Professor Herbert Osborn. 


\section{THE EUGLENA}

I have generally been able to get the Euglena by this method: place pieces of bark an inch or more square, preferably from the edge of a pond, in the middle of a beaker or jar holding a pint or more of water. Set the culture vessel in a north window and let it stand. In a few weeks examine the upper and under surfaces of the pieces on the bottom, and you are likely to find Euglena viridis.

Euglenæ are also likely to be found on the sides and bottoms of many small aquaria. I have had fine lots of them develop in closed glass plant boxes, which had been temporarily used for keeping frogs. In small salt-water aquaria containing horse-shoe crabs they have also developed in great abundance.

I have alsó obtained a fine lot of Euglena viridis in this way: a glass

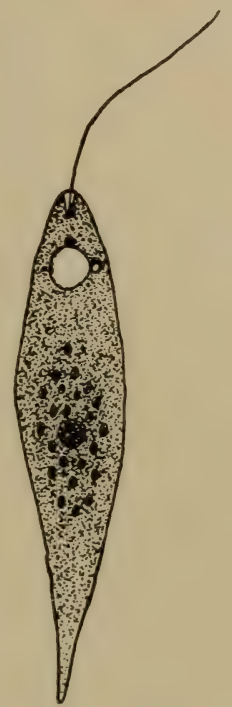

The GREen Euglena : Active form. Magnified.

dish two inches high by six inches in diameter was twothirds filled with vegetable debris - largely pond, scum from an old spring. It was then filled with water, covered, and placed near a window. After standing undisturbed nearly two months, a thick whitish scum had developed on top, and on the sides of the dish at the surface of the water there was a green growth composed almost entirely of euglenæ.

In summer and autumn the standing water in the vicinity of barnyards is frequently full of euglenæ in 

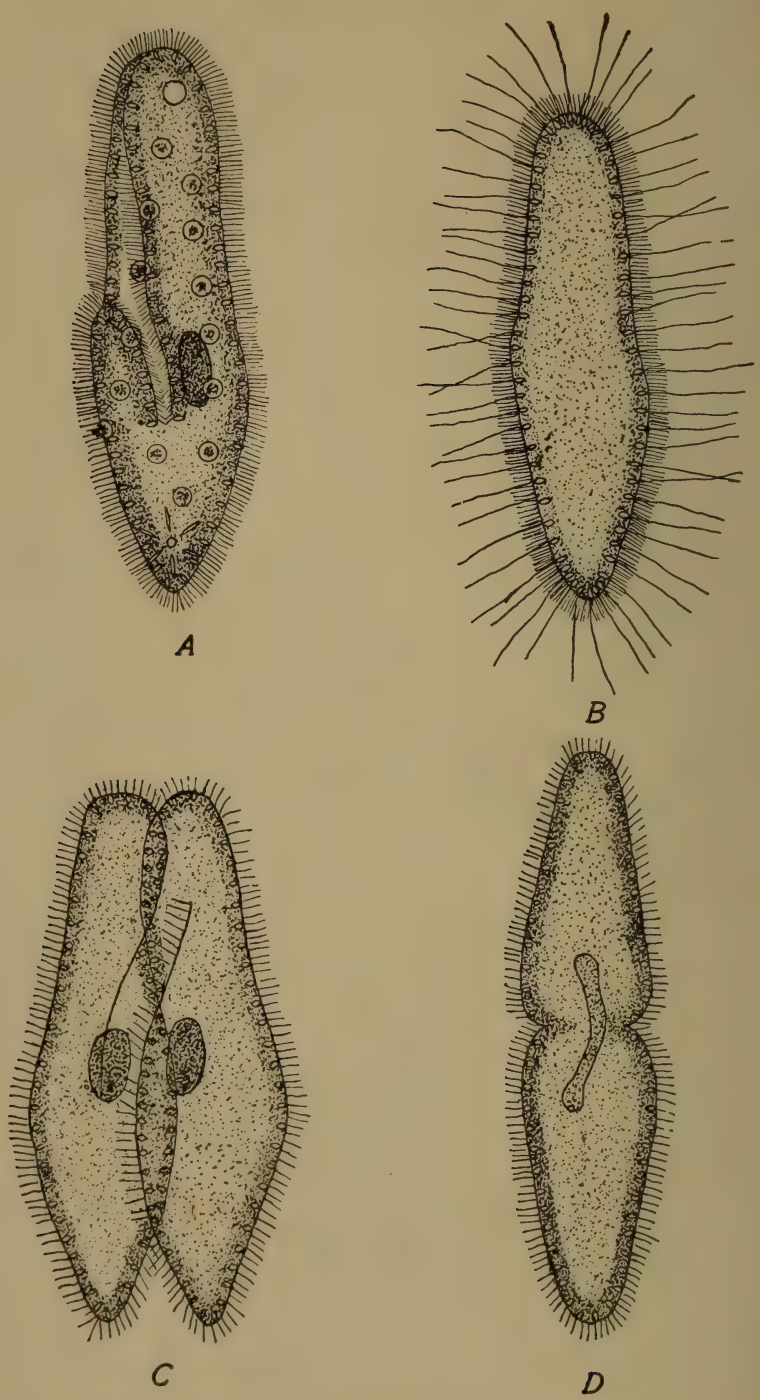

The PARAmecium: $A$, normal active form; $B$, after treatment with acetic acid to bring out trichocyst threads; $C$, conjugating specimens; $D$, early stage of fission. Magnified. 
excellent condition for study. Water from such a situation may be placed in jars indoors, and allowed to stand some time with good results.

\section{THE PARAMECIUM}

Paramecia may commonly be developed by putting an excess of pond-scum or other water plants in a vessel containing water and setting the vessel in a warm, dark closet for a week. There will then probably be a whitish film on top of the jar; in this film you are likely to find an abundance of paramecia. Keep the jar in a warm, dark situation and they will continue to develop for some time.

One of the finest lots of paramecia I have ever seen was developed in the following way: a cylindrical jar holding about two gallons ( inches high) was nearly filled with water and then was stocked with a mass of CEdogonium and other fresh-water algæ, obtained from a spring, October 22. An excess of this was put in, and the jar was placed in a well-lighted room, six feet from a window. Five days later a rather thick film had formed on the top; it contained an abundance of large bacteria of various forms, a number of ciliate and flagellate protozoa, a few desmids and diatoms, as well as an occasional protococcus-like form. The sides of the jar showed bacteria, desmids, diatoms, Protococcus, Hæmatococcus, and a few euglenæ. The bottom showed an abundance of the same forms. After this examination (October 27) I covered the jar and put it in a dark closet. On November I another examination was made. The white film showed many ciliate infusoria, including some fine paramecia. Ten days later the water 
was alive with splendid examples of typical paramecia, white in color, which showed plainly the details of structure. Along the sides of the glass, just below the surface of the water, a white ring was visible to the naked eye, which under the lens was seen to be composed entirely of these paramecia, and the sides of the jar were also covered with colonies of Stentor polymorphus. In many cultures since then I have obtained these rings of paramecia. From such rings, hundreds of specimens may easily be transferred to the slide by means of a camel's-hair brush or a medicine dropper.

Paramecia are also likely to be found in many small aquaria; they are often abundant in those in which clams have been kept. But they can be studied to much better purpose when they are so abundant that one can have the large typical specimens in quantity.

The course of the food-balls in the body may be admirably shown by this method: place a lot of paramecia in a watch glass with a small quantity of water; add a little powdered carmine to the water; cover, and examine fresh specimens at intervals of ten minutes for an hour or more. You will be able to trace the whole course of the food-balls in this way.

The nucleus of Paramecium may be brought out by staining with iodine, magenta, methyl-green, or other stains. The trichocyst threads may be brought out by running under the cover glass a dilute solution of osmic, picric, or acetic acid. The form of the body is sometimes well shown when Schultze's solution is added.

Paramecia should be first studied under the low powers with little or no cover-glass pressure. The normal shape can then be seen. The pressure of the cover glass flattens the body. By placing a little cotton-wool beneath the 
cover glass the movements of the paramecia may be restricted so that they are more easily studied.

\section{THE VORTICELLA}

Vorticellæ occur in nature in ponds and sluggish streams, but are difficult to find in such situations in sufficient quantity for class use. They may be cultivated in aquaria without difficulty. They are likely to develop in shallow dishes containing aquatic plants of any kind, especially if the dish be placed in a dark situation. In the aquarium in which such a great quantity of paramecia were developed, as described above, large numbers of vorticellæ were also produced. Several cultures of vorticellæ are desirable in order to get the dividing, the free-swimming, and the encysted stages. I have repeatedly obtained cultures showing each of these forms, the

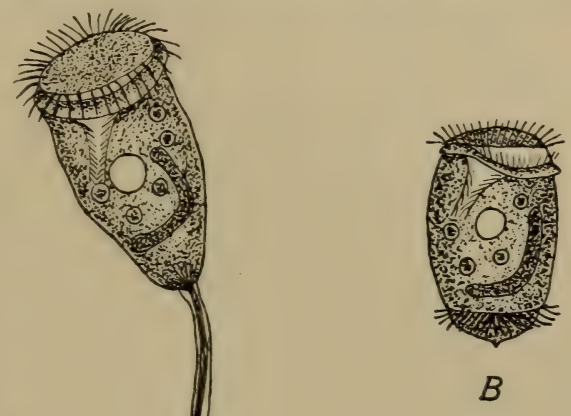
seeing of which adds much to the value of the study by the class. 


\section{THE STENTOR AND STYLONYCHIA}

Stentors are generally harder to develop in indoor cultures than the common infusoria. But I have usually had them present in some one of the culture jars, frequently in those in which paramecia are found. Stylonychia is also generally present in Paramecium cultures.

\section{SPONGES}

Fresh-water sponges occur as bright green growths attached to stones and wood in shallow streams. The shade of the green is different from anything else in the environment, and together with the distinct spongy feeling of the organism will enable any one to recognize it. It frequently spreads over a considerable surface.

These sponges are common in brooks, and may generally be found in abundance in the little pools between the large stones where the stream is rapid. They should be studied fresh, as they do not bear confinement in standing water very well. The gemmules occur late in autumn.

The salt-water sponges are common along the coast, and may easily be gotten from pools when the tide is out. For inland schools they may be purchased of dealers in biological supplies.

\section{HYDRA}

This creature has a small cylindrical body, by the base of which it attaches itself to various objects in the water, and from the other end of which project a number of tentacles. Both the body and the tentacles are capable of being expanded and contracted, so that sometimes they 
are long and slender, and at other times short and thick. Their appearance when slightly magnified is shown in the figure herewith. Two species are commonly found : in one the body is green; in the other it is light brown.

Hydras are common in ponds and ditches, but are difficult to obtain in quantities under natural conditions. To collect them the following method is recommended:

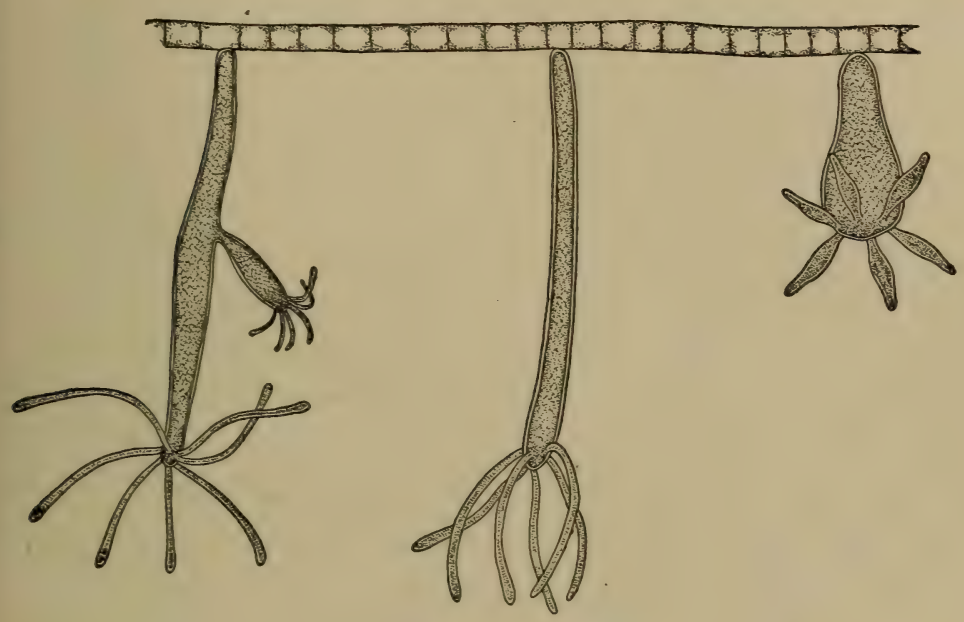

The Hydra. Magnified.

Bring in from various situations in ponds or sluggish streams small quantities of water-weeds, - as Nitella, Spirogyra, or Vaucheria, - collecting them with a small quantity of water in jars or cans, and labelling each so as to know where it came from. Place the material of each collection in a jar of clear water near a window, and let it stand for a day or two. Then examine the jar carefully, especially the sides near the window, for hydras. In this a reading glass is very helpful. In case hydras are found 
in one jar, get more of the material from the same place and treat it in the same way. The hydras may be transferred to covered aquaria containing Vaucheria, Nitella, or similar plants, where under favorable conditions they will multiply and be available when wanted.

With a dozen or more aquaria containing water plants

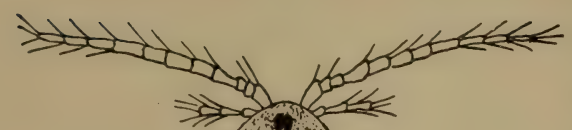
in good condition in the laboratory, hydras are pretty sure to be present in some of them. Water snails should not be allowed in hydra jars. Cyclops or other minute crustacea are also likely to be found in some of these jars.

Marine Animals. - The various marine forms treated of in this book may be purchased in good condition for study, at small expense, from the Supply Department, Marine Biological Laboratory, Woods Holl, Mass., as well as from various other dealers in such materials.

\section{INSECTS}

It is of course necessary that insects should be collected during the season when they are abundant. Some of them, 
like beetles, grasshoppers, and crickets, may be preserved in alcohol; while others, like the butterflies, may be kept dry, although part of these may well be preserved in alcohol. To collect many of the insects a net is needed. To make it, obtain an iron wire about a fifth of an inch in diameter, bend it into a ring about a foot in diameter, with the ends projecting two or three inches at right angles; solder the ends into a short piece of brass tubing. Then sew over the wire a strip of strong muslin an inch or two wide, and to this muslin sew a bag of mosquito netting, Swiss muslin, or some similar fabric, about thirty inches deep. When in the field ready to collect, cut a handle for the net, or make one beforehand that will fit into the piece of brass tubing.

The most convenient method of killing insects is by the use of the cyanide bottle. To make this, take almost any wide-mouthed glass bottle with a tight-fitting cork. Place on the bottom two or three lumps of cyanide of potassium (a virulent poison to be handled with great care), the size of a hickory nut, cover these with fine sawdust, and over the sawdust pour in sufficient plaster of Paris mixed with water to make a layer half an inch thick. Let the bottle dry out before inserting the cork. As already stated this cyanide of potassium is poisonous, and of course must be handled carefully. If desired, the bottles may be prepared at drug stores at small cost. After the plaster is set, there is practically no danger unless the fumes of the bottle be directly inhaled, for which there is no excuse. Keep the bottle closed except when putting in an insect. The cyanide fumes rising through the porous plaster will kill it almost instantly. This cyanide bottle is to be used especially for butterflies and moths, as well as for bees, wasps, and similar insects, but should not be used for worms and caterpillars, 
which are more successfully killed and preserved in alcohol.

Insects which have been kept dry for some time should be placed in a moist chamber (a tight jar with a little water or a damp sponge in it) for several hours to soften them before being used.

Crayfishes for class use are easily obtained in many parts of the United States. In the Eastern States, where it is more difficult to get them, they may be bought of the following firms : Middleton, Carman \& Co., Fulton Market, New York, N.Y., or Shattuck and Jones, Faneuil Hall Market, Boston, Mass.

Live lobsters may also be bought of these or other merchants, but the crayfishes are less expensive and more convenient for study. - c. м. w. 
A LABORATORY GUIDE FOR BEGINNERS IN ZOOLOGY 



\section{LABORATORY GUIDE IN ZOOLOGY}

\section{CHAPTER I}

\section{BRANCH PROTOZOA: THE ONE-CELLED ANIMALS}

\section{THE AMGEBA}

IT is very desirable that good-sized specimens be provided for the study of the Amœba. Under the high power of the microscope look for a small, granular, nearly transparent object, which changes its outline either constantly or at frequent intervals.

I. - Notice the general nature of the movements. Are they slow or fast? Does the Amœba always move in a definite direction? Does it ever happen that different parts of the body move in different directions at the same time? Make five outline sketches showing the changes undergone by one Amœba.

II. - Study the method by which movement takes place. See that the outer colorless layer of protoplasm - the ectosarc - rolls out into one or more blunt projections, called pseudopodia, or false feet. See whether the inner, more granular protoplasm - the endosarc - is forced into the pseudopods by the lateral pressure of the ectosarc. Observe the changes in the outline of the body due to the movement of the pseudopods. In 
case the Amœba is moving in a definite direction, notice whether the progress is being made by means of a single broad pseudopod or by more than one. Determine whether a change in the direction of movement is made by pushing any part of the surface of the protoplasm outward. Is it true that the body of the animal is thus temporarily differentiated into anterior and posterior parts?

III. - Watch the Amœba as it approaches some small, one-celled plant. Wait patiently to see, if possible, the plant-cell taken into the body of the Amœba: How is this accomplished? Is any water taken into the body with the plant-cell?

IV. - Focus carefully upon a round, nearly transparent spot generally to be seen in the ectosarc: this is the contractile vacuole. Watch this spot patiently to see whether it ever disappears. If it does thus disappear, watch for its reappearance.

V. - In the largest specimens look for the roundish nucleus, more granular than the endosarc surrounding it. If it is not visible in the living Amœba, stain the specimen with iodine or carmine to bring it out.

VI. - One is rarely fortunate enough to see the process of fission in the Amœba, but sometimes this happens. If a large Amœba is seen partially divided near the middle, watch it closely to see if division is taking place; if so, continue watching until the process is completed.

VII.-Draw an Amœba, making the sketch at least an inch in diameter: show its form, the distinction between the ectosarc and endosarc, the contractile vacuole, and the nucleus. 


\section{Branch Protozoa}

\section{THE EUGLENA}

The Euglena may be found in a resting or active condition; if resting, its form is generally almost or quite spherical. In finding and studying it, use the high power of the microscope.

I. - Study the free-swimming movements of the active organisms: do they always move straight ahead, or do they sometimes twist and turn about? Watch the euglenoid contortions of the body; make five outline sketches showing the changes undergone by a single specimen. See whether the shape assumed when swimming freely straight ahead is generally the same in different individuals. Distinguish between the anterior and posterior ends of the body. Watch the animal turn round and round on its longitudinal axis: does it show any differentiation into dorsal and ventral regions?

II. - The direct cause of locomotion will be found in the constant vibratory movement of a single hair-like process, about one-half as long as the body and projecting from the anterior end. It is to be seen most plainly in the largest specimens. This is the flagellum: it is a part of the protoplasm of the body, differentiated for the purpose of locomotion; it is permanent in the active form of the Euglena, and cannot be withdrawn like the pseudopod of the Amœba. By careful focussing, one can get glimpses of the cone-like cavity with the apex pointing inward, from the inner end of which the flagellum arises. This cavity serves the purpose of mouth and gullet, into which the vibration of the flagellum brings particles that serve as food. See the vortex in the water caused by the movement of the flagellum. 
III. - Notice the green color of the Euglena due to chlorophyl - the green coloring-matter of plants. By means of this the creature is able to build up its substance as plants do. Add a little alcohol, and notice what effect it has upon the color of the Euglena.

IV. - After the alcohol has thus been added, notice the oblong bodies near the middle of the Euglena: these are paramylum grains.

V. - In a freshly mounted specimen study the protoplasm at each end of the body. How does its color differ from that of the central part of the body? Near the front end see a distinct red spot, often called the eye-spot. Near this eye-spot distinguish the large clear reservoir with the vacuole beside it. The distinction between these may be plainly seen only in the largest and best specimens.

VI. - Stain the specimens with iodine or carmine; then look for the nucleus, a round spot near the middle of the body. If it does not show clearly, take a fresh slide, treat with alcohol to dissolve out the chlorophyll, and then stain.

VII. - Make a drawing at least an inch long, showing an outline of a free-swimming Euglena and all the structural details you have seen.

VIII. - Study as many stages of the round Euglenas undergoing fission as you can find. Make sketches of two or three specimens showing different phases of the process. 


\section{Branch Protozoa}

\section{THE PARAMECIUM, OR SLIPPER ANIMALCULE}

For a successful study of the Paramecium we must observe the animal alive in water. Find it with the low power: it will appear as a slipper-shaped creature swimming rapidly about. To prevent its escape from the field of vision so that it may be studied with the high power, it is often desirable to put a few fibres of cotton under the cover glass. The same end may also be accomplished by drawing off much of the water on the slide by means of blotting-paper, but one should remember that the pressure of the cover glass may thus flatten the Paramecium.

I. - Determine whether the animal moves in a definite direction without changing its outline. Does it move both backward and forward? By focussing carefully, with light from the small opening of the diaphragm, determine the cause of movement. The short delicate hair-like processes around the margin of the body are called cilia. Do they vibrate when the animal moves? Can you see any difference in the motion of the cilia when the animal is going forward and backward?

II. - Study the animal as it swims: does it revolve on its longitudinal axis? Can you see a spiral groove on one side of the body? It is called the buccal-groove. How long is this groove as compared with the body?

III. - Watch the Paramecium as it moves in and out among the particles on the slide. How does its flexibility compare with that of the Amøeba? See whether the liquid endosarc flows back and forth within the body in response to the pressure of the ectosarc.

IV. - Determine whether locomotion is made with either end foremost. Is the blunter or the more pointed end 
usually ahead? In case either of these is generally in advance there is a differentiation into anterior and posterior parts of the body.

V. - As the Paramecium turns on its longer axis, notice whether the edges of the buccal-groove are covered with cilia ; are these longer than those on the rest of the body? Are they constantly in motion? Focus carefully to see the gullet connecting the buccal-groove with the interior of the body. Is this also lined with cilia in motion?

VI. - Run some powdered carmine under the cover glass: when the particles have reached the Paramecium, watch carefully to see some of them taken along the buccal-groove through the gullet and into the body. Notice that a little water goes in also, forming a small, round food-ball that stops near the inner end of the gullet, surrounded by the semi-liquid endosarc. When another food-ball is taken in, the first one will be forced along, keeping near the side of the body. When a third mass is taken in, both the others will be pushed along, and thus the process will continue, the masses following a definite course around the outer border of the endosarc.

VII. - The course of the food-balls in the body may be easily shown in this way: Place a lot of Paramecia in a watch glass with a small quantity of water; add a little powdered carmine to the water; cover, and examine fresh specimens at intervals of ten minutes for an hour or more. You will be able to trace the whole course of the food-balls by this method.

VIII. - See the two round, nearly transparent contractile vacuoles near the side of body, each about halfway between the middle and the end. Watch them care- 
fully, to see the contraction: as the round spot disappears see the radiating canals surrounding it. Then see the expansion by which the vacuole resumes its former shape and size.

IX. - The egestion of indigestible material may sometimes be seen by patient observation. Watch one or more particles that have completed the circuit which the food-balls follow, and have come to rest near the posterior end of the body. If you are fortunate, you will see a slight movement of the inner protoplasm, and the particles in question will suddenly be seen lying on the outside of the animal. As no opening in the body wall is visible, it is evident that the particles passed through a temporary opening. Since this usually takes place at the same spot, it is probable that the body wall is adapted at this point to the performance of this function.

X. - Stain the Paramecium with iodine by putting a drop of the coloring-matter on the slide, and drawing it under the cover glass with blotting-paper. This will bring into view a large nucleus, generally near the gullet: and perhaps also the smaller micronucleus, lying beside the nucleus.

XI. - With a fresh mount, focus carefully along the side of the body to see the short, dark, oval trichocysts, perpendicular to the surface. Run a little dilute acetic acid under the cover glass, and watch the long, hairlike processes - the trichocyst threads - thrown out from the surface of the body.

XII. - Should you see one of the Paramecia with a constriction on each side of the body at the middle, observe it closely: it is undergoing fission, the simplest method of reproduction employed by this species. 
XIII. - Draw a Paramecium, showing the structure as you have observed it. Make the sketch at least two inches long.

\section{THE VORTICELLA, OR BELL ANIMALCULE}

The Vorticella is usually attached by one end to some stationary object. Its movements thus being confined to a narrow range, it is comparatively easy to study under high powers of the microscope.

I. - Notice the two principal divisions - body and stalk. Compare the animal with a bell, and see at what part of the bell the stalk is attached: this part is called the proximal end. Tap the cover glass gently, and notice the sudden contraction of the stalk into a spiral and the change in the shape of the body. Watch the creature as the stalk straightens out and the body resumes its previous shape.

II. - Focus carefully on the stalk to determine its structure. Can you see a slender band - the axial fibre - on the inside of the cylindrical outer portion?

III. - Study the outer or distal end of the body. Watch the ring of cilia immediately within the enlarged edge of the bell - called the peristome - within and partly attached to which is a flattened disk. Between the edge of the disk and the peristome on one side, is the mouth, which leads into the gullet. The latter is lined with cilia, and leads directly to the inner protoplasm of the body. Add a little powdered carmine to the slide, and see if you can observe the taking in of the food.

IV. - A contractile vacuole may be seen in the body near the gullet. Watch its action. Distinguish also, if you 
can, in the living Vorticella the long, curved, horseshoeshaped nucleus. If it is not seen, stain the specimen to bring it out.

V. - You are likely to find sometimes two Vorticellas upon the same stalk: this represents the last stage of fission. Sometimes other stages of division will be found, and occasionally a free-swimming Vorticella may be seen, with a ring of cilia around the posterior margin.

VI. - Make a good-sized drawing of a Vorticella, and sketches of any of the reproductive phases you may have found.

\section{THE STENTOR}

Although at times the Stentor is a free-swimming body, moving around as readily as the Paramecium, when found attached it may be studied as easily as the Vorticella, which it resembles somewhat in shape. It is one of the largest of the Infusoria, being easily visible to the naked eye.

I. - Find the Stentor and study its movements with the low power. Note the various shapes that it assumes: sometimes it appears as a long, blunt, revolving cylinder, swimming through the water; at others, it stretches out and becomes pear-shaped, usually being attached at such times to some object by its smaller end.

II. - When a Stentor thus becomes attached, study it carefully. See the movements of expansion and contraction. Observe the anterior disk, and the cilia encircling it. Add a little powdered carmine to the slide to demonstrate the manner of feeding; see the particles pass down the spiral groove into the endoplasm, where they become a food-ball which is pushed farther into the protoplasm as time goes on. 
III. - Study the contractile vacuoles. How many can you find?

IV. - Near the middle or front of the body find a mass of food material contained in a well-defined spherical cavity, somewhat larger than the contractile vacuole. This is called the excrement vacuole. Indigestible matter from all parts of the body is forced into this vacuole, whence it is extruded through the body wall. Egestion may, however, take place at other points.

V. - By careful focussing, make out the longitudinal striations of the Stentor. These are due to a differentiated portion of the ectosarc, by the contraction of which shortening of the body takes place. Determine whether there are cilia all over the surface of the body.

VI. - See the remarkable chain-like nucleus along one side of the body. It can frequently be distinguished before staining, but if it is not visible in your specimen, add some staining solution to bring it out.

VII. - Make a good-sized drawing of the Stentor, showing the parts visible when it is stretched out. Make also a sketch showing its shape when contracted.

\section{THE STYLONYCHIA}

In the first search for Stylonychia remember that it is shorter than the Paramecium, although it resembles the latter somewhat in general shape.

I. - Observe the quick, jerking movement in its locomotion. By the use of a bit of blotting-paper, draw out some of the water on the slide, to restrain its movements so that it may be studied with the high power. Watch the animal carefully to determine its anterior and posterior ends. Try to see if there is a rotary movement of the body. Determine whether it has a dorsal and a ventral side. 
II. - Watch the motion of the cilia on the surface of the body, and see the effect produced by such motion. If the Stylonychia forces itself along among the particles on the slide, notice the flexibility of the body.

III. - Find two or three groups of spine-like processes much larger than the cilia. Are they movable? See if you can determine their use.

IV. - Find the gullet, appearing as a light streak near the centre of the body. Notice the motion within the gullet. Trace the buccal-groove from the gullet to the end of the body. Observe the enlarged cilia along it. Observe the relation between the buccal-groove and the direction in which the creature moves.

V. - Run a little powdered carmine under the cover glass. Wait a little until it reaches the Stylonychia; then see if you can observe the passage of some of the particles into the body. By patient watching, the course of the food masses through the body may be traced, the process being similar to that already seen in the Paramecium. VI. - The indigestible particles are forced out through the ectosarc near the posterior end. Find if you can a mass of particles to be egested; observe intently the surface near the base of the spines, and quick, jerky twitchings of the protoplasm will be seen; this forces out the particles.

VII. - Observe the contractile vacuole and the two large nuclei; to see the latter, it may be necessary to use a staining solution.

VIII. - Draw a Stylonychia, showing the structural characters you have seen. Make the sketch at least an inch long. 


\section{THE CLASSIFICATION OF THE PROTOZOA}

The lowest branch of the animal kingdom is the Protozoa. The members of this branch are nearly all aquatic, microscopic animals of very simple structure. They consist of a single cell, or in some cases of an association of cells, which are not, however, distinctly differentiated into tissues. The animals of this branch consist essentially of bits of protoplasm, each capable of absorbing food and reproducing its kind. Food is taken into the body; its digestible portions are assimilated, and its indigestible parts are rejected. The food so utilized may be either animal or vegetable in its nature.

The Protozoa may be reproduced by fission, a process of simple division; by budding, a process in which a small portion of the animal is divided off, separating from the parent cell, and finally developing into a new organism; and by conjugation, a sexual process by which in certain forms two or more individuals fuse together, become encysted, and later split up into a large number of spores, each of which develops into an adult organism. There are various modifications of each of these processes.

The Protozoa are now divided by leading authorities into five classes, namely :-

I. Rhizopoda.

II. Mycetozoa.

III. Mastigophora.

IV. Sporozoa.

V. Infusoria.

The members of the lowest class of Protozoa, the Rhizopoda, are usually characterized by the presence of an outer layer of protoplasm which frequently sends out 
temporary processes. The Amœba is a typical example of this class, having a nucleus, nucleolus, and contractile vacuole. Under unfavorable conditions the Amœba may become encysted and remain in that condition for a long time. Many Rhizopods are marine, secreting a covering or shell of carbonate of lime. The shells, falling to the ocean bottom when the animals die, in the course of geologic ages form vast areas of rock. Some of the most important animals carrying on this work are members of the order Foraminifera.

The second class, Mycetozoa, consists of a group of organisms which are often included by botanists among plants, and called "slime-fungi." They so combine the characters of animals and plants that it is very difficult to say definitely to which kingdom they belong. They live upon decaying organic matter - such as leaves or damp wood, where they appear spread out in thin sheets of jelly-like protoplasm.

The Euglena is a typical example of the third class, Mastigophora. The members of this group were formerly. united with the Paramecium and similar animals to form the class Infusoria. Now, however, those creatures furnished with flagella are included in the Mastigophora.

The fourth class, Sporozoa, consists of microscopic creatures living as parasites within other animals. The best known examples belong to the order Gregarinida, and live in the intestines of various insects and other Arthropods and worms.

The members of the fifth class, the Infusoria, represent the highest Protozoa. In these the protoplasm of the cell is generally differentiated on the outside into a somewhat hardened covering, inside of which is the more fluid protoplasm. All the members of this class are pro- 


\section{I4 \\ Laboratory Guide in Zoology}

vided with short filamentous processes called cilia, which are outgrowths of the ectosarc. In some species, these cilia remain during the entire life of the animal, while in others they are present only in the young, being replaced in later life by peculiar organs called tentacles. The Paramecium, Vorticella, Stylonychia, etc., are examples of this class. 


\section{CHAPTER II}

\section{BRANCH PORIFERA: THE SPONGES}

\section{THE FRESH-WATER SPONGE}

UpoN the stones of clear running streams one can commonly see a greenish growth which at first sight is likely to be taken for an aquatic plant. If you rub your fingers upon it, however, you will notice a peculiar spongy feeling, and looking closely will find it very different from a plant. It is rather an example of the Fresh-water Sponge. Its more important features may be determined by means of the following outline :-

I. - Study and describe the living sponge: its color, shape, size, surface appearance, and mode of attachment to the object on which it rests. In living specimens or those preserved in formalin, notice with a lens the minute openings in the surface, and see that there are two sets of holes, one larger than the other. Water containing food material enters the internal cavities through the smaller and goes out through the larger openings, the currents being produced by ciliated cells lining the passages. Observe also the tiny projecting spicules which form the skeleton of the sponge.

II. - Feel the sponge with the tips of your fingers, noting the peculiar spongy texture.

III. - Place a very small piece of the living sponge upon a glass slide; tease it out with needle points, put on the cover glass, press it down firmly, and examine under 
the high power the margins of the sponge. You are likely first to see great numbers of very small, round, greenish cells; these are a species of one-celled alga a microscopic plant - which develops in connection with the sponge. Notice, also, certain much larger, spherical, granular cells, having somewhat the appearance of a resting Amœba. Imbedded in the protoplasm of these cells, there are likely to be many of the microscopic algæ just mentioned. These larger cells are the ones that form the sponge "flesh." Some of them are likely to show movements similar to those of the Amœba, and in consequence they are called amœboid cells. Make drawings of one or more of them.

IV. - Examine the margin of the particle of sponge: notice the soft cells connected with the whitish, needlelike spicules.

V. - Place a small piece of sponge in caustic potash in a watch glass for an hour, then study the spicules under the microscope, after they have become separated from the tissues. Make drawings of three or four of them.

VI. - Sponges collected during autumn and winter are likely to show peculiar yellowish spherical gemmules in the body. These are reproductive bodies by means of which the sponge passes through the winter.

\section{THE SIMPLE MARINE SPONGE}

\section{(GRANTIA SP.)}

This sponge is a marine animal, found commonly along the Atlantic coast of the United States.

I. - Make a careful drawing of your specimen as seen through a hand lens of low power. Show in the drawing these parts:- 
a. The general outline of the body, with its surface roughened by the presence of innumerable spicules.

b. Beneath the rough surface of the spicules see the inhalent pores, scattered thickly over the wall of the sponge.

c. The expansions at the basal end by which it is attached to the object upon which it grows.

d. The terminal osculum, the opening at the upper or distal end surrounded by a funnel-like circlet of spicules.

II. - Make with a sharp scalpel a longitudinal section of the sponge. Observe:-

a. The central cavity into which the osculum opens; this cavity is called the cloaca.

$b$. The many minute openings through the inside wall of the sponge are called the gastric ostia.

c. In the cut surface of the sponge the numerous parallel canals, which connect the inhalent pores with the ostia. Make a diagrammatic drawing showing the structure of the sponge when thus seen in a longitudinal section.

III. - Mount some of the spicules from the inside and outside of the sponge and examine with compound microscope. Is there any difference in the appearance of those from the two situations? Draw specimens of each.

This is an example of sponge life. The body is supported by the skeleton of spicules. Water containing microscopic plants or animals which serve as food is drawn through the inhalent pores into the parallel canals, where some of the food particles are taken up by certain cells. Then the water goes on through the ostia into the cloaca, and later passes out through the large osculum. 


\section{THE CLASSIFICATION OF THE PORIFERA}

The animal kingdom as a whole is broadly divided into two great groups, - the Protozoa, or one-celled animals, and the Metazoa, or many-celled animals. The examples treated of in Chapter I. all belong to the Protozoa, while the sponge is the first example of the Metazoa.

The Porifera (formerly called sometimes Spongida) is the second phylum or branch of the animal kingdom, and the lowest of the Metazoa.

For a long time in the early history of science the real nature of sponges was not understood. Naturalists could not agree as to whether they were plants or animals, or part plant and part animal. It has, however, been acknowledged for many years that they belong to the animal kingdom. After this point was reached there was much discussion as to their place in the kingdom. Some zoologists believed that they were simply masses of singlecelled individuals living together, each for and by itself : consequently they placed the sponges in the Protozoa. It is now known, however, that a single sponge individual is made up of a great number of cells, all working for a common end - the existence of the sponge individual. To do this well, some of the cells perform the function of protection, some that of nutrition, while others serve the purpose of reproduction. In other words, the cells of the sponge organism are differentiated into tissues, those doing the same kind of work forming the same tissue.

Sponges are aquatic animals of wide distribution: although most abundant in salt water, a few small chlorophyl-bearing species live in fresh-water brooks and other streams. Their lives, except when they are very young, are spent attached to some submerged object where micro- 
scopic animal and plant life is abundant. Sponges as we ordinarily see them, either while living or after they have been treated for commercial purposes, convey to us no idea of the typical structure of the sponge. A bathing sponge, for instance, instead of being a sponge individual, is a colony of individuals formed by the budding and branching of an original sponge individual. The typical sponge has but one large crater-like opening at its top, and several smaller openings on its sides. Water currents enter the smaller openings, pass through the canals to an interior cavity and escape through the large opening called the osculum. Food contained in the water is absorbed by the cells as it passes through the water-courses. The 'outer covering of the body, the ectoderm, is a delicate membrane composed of a single layer of flat cells. A similar layer, the endoderm, lines the interior cavity and the canals leading to it. Between these is the mesoderm, some of the cells of which have developed horny fibres, or siliceous or calcareous spicules, which serve the purpose of a skeleton that is seen in commercial sponges, the living cells having been rotted and washed away. 


\section{CHAPTER III}

BRANCH CELENTERATA: THE HYDRAS AND THE SEAANEMONES

\section{THE FRESH-WATER HYDRA}

EITHER the green or the brown Hydra may be used for this study. Before the specimen is placed upon the slide beneath the microscope it is desirable that the student examine the specimens in the culture vessel. Notice their color, general shape, and mode of attachment. With a camel's-hair brush or small glass tube, remove the Hydra to a watch glass or a glass slide with a hollow cell, holding a little water, and study it with the low power of the microscope.

I. - Observe the general form of the Hydra, noticing the shape of the body and of the projections, called tentacles, at its upper end. See that the most noticeable movements are the gentle lashings of these tentacles.

II. - Study and describe the contraction and expansion of the body and of the tentacles. These movements are caused by the contractile power of muscle processes attached to the inner ends of those cells which form the outer layer of the body wall.

III. - Sometimes the Hydra moves from place to place by bending the body into a loop and using each end as a foot. This is not usually to be seen, however.

IV. - Watch again the slow sweeping movements of the tentacles. Possibly you may see one tentacle lay hold upon a small water-flea or other particle of food. If so, 
it is likely to pass the food to the base of the tentacle, where, in the middle of a round projection, the mouth, opening into the body cavity, may be seen.

V. - Make another careful study of the Hydra, endeavoring to see the hollow nature of its body and tentacles. This may sometimes be done by strong light when the animal is extended. Is the body cavity continued into the tentacles? Encircled by the bases of the tentacles, see a cone-shaped extension of the body, the hypostome. How is the mouth situated with reference to the hypostome? Unless you are fortunate in retaining the specimen in the right position, it will require careful manipulation with needles or other instruments in order to see clearly the mouth opening.

VI. - See that the walls of the Hydra's body and tentacles are made up of two layers of cells: the inner layer is called the endoderm, and the outer layer, the ectoderm. The colored appearance of the green Hydra is due to the pigmented chlorophyl. Focus carefully with strong light along the edge of the body or tentacles, to determine whether this chlorophyl is contained within the ectoderm or the endoderm. Make a drawing to show the double or diploblastic nature of the body wall. VII. - Notice that the mouth furnishes the only entrance to the body cavity, which serves as a stomach. Food is pushed in by the tentacles through the mouth, and through it the indigestible matter is ejected by the contraction of the body. Note the fact that the food comes in contact with the endodermal cells only. These cells alone perform the function of digestion, and thereby exhibit a true division of labor among the cells of the organism. The ectodermal cells obtain their food only after it has been digested and passed through 
the endoderm. True excretion, or the removal of waste material produced by chemical changes within the cells, is performed by the general surface of the body.

VIII. - In the ectoderm of the tentacles try to find small, well-defined oval bodies near the margin. They are called nematocysts, are contained within nettle cells, and correspond in function to the trichocysts of the Paramecium. Within this oval sac there is a long, spirally coiled thread which the Hydra has the power of throwing out to wound its prey. Doubtless some poison ejected with the thread produces the wound. These organs are put to great use in capturing food, though none can be used a second time. You may see the threads by drawing acetic acid under the cover glass.

IX. - Observe the Hydras in the culture jar once more. Try to find one that has a blunt projection on the side of its body or one that has a small Hydra attached to it. These are doubtless stages in the process of reproduction by the asexual method. There is also another way in which Hydras reproduce their kind - the sexual method. These processes are explained in the following sections.

X. - Asexual Reproduction. Multiplication by this process is called budding. A blunt process or bud appears on the Hydra's side, formed at first only of ectodermal cells. This is gradually pushed out and filled with endodermal cells. As the bud increases in size, a cavity, continuous with that of the main body cavity of the parent Hydra, is developed within the mass of endoderm. Later a mouth and tentacles are formed at the outer end of the bud; its stalk is then constricted at its union with the parent, and the free-swimming young Hydra moves away. Some stages of this process of budding may be easily found by examining all the specimens at hand. 
XI. - Sexual Reproduction. Light-colored blunt processes formed only of ectodermal cells appear on the body near the tentacles. Such structures are the male reproductive bodies and are called spermaries. Their inner cells change into sperms, and when the thin wall holding them bursts, they go forth as free-swimming, pointed masses of protoplasm.

XII. - Elevations similar to the spermaries also occur near the basal end of the body. These are the ovaries, and are at first similar in structure to the spermaries. Their inner cells soqn disappear, with the exception of one large amœboid cell, called the ovum. This soon becomes freed from the Hydra, and is penetrated by a single sperm from some other Hydra. The process is called fertilization, and the fertilized ovum sinks to a sheltered place and soon develops into a Hydra.

You will probably be unable to study this process by actual observation, since it is much more hidden and complex than that of budding. Any slight swellings on the side of the Hydras should, however, be carefully studied, although it may be hard to distinguish between ovaries, spermaries, and young buds.

\section{THE CAMPANULARIAN HYDROID}

HYDRIFORM STAGE

This little animal lives in colonies in shallow water along the seashore.

I. - Examine through a hand lens or with the low power the specimen in your watch glass. Notice its general appearance. Is it attached to anything? Is there any variation in the color? Observe the size of your specimen. 
II. - Mount the specimen on a glass slide and observe it through the low power. Notice that the animal is composed of two general parts ; namely:-

a. A firm outer covering, called the perisarc.

b. An inner protoplasmic part - the living substance.

III. - Identify the following five general divisions of the perisarc :-

a. The root-like expansion, called the hydrorhiza, by which the stem is attached to whatever object it grows upon.

$b$. The upright stem portion, forming the linear cylindrical part of the colony. This is the hydrocaulus.

c. The branches that have an open, conical, bell-like projection on the outer ends, inside of which are small hydra-like bodies with numerous tentacles: the projecting parts of the perisarc are called hydrothecæ, and the hydra-like bodies are called zooids or hydranths.

d. Branches like those just described, but closed at the outer ends and having protoplasm inside: these are young hydranths in process of development.

$e$. Branches that have a club-shaped tip, the gonangium, inside of which are small, rounded bodies, the medusa-buds.

Make a drawing showing each of these parts and label them distinctly.

IV. - Study the structure of the perisarc. Notice its thickness. Is it perfectly cylindrical throughout its length? If not, where are the variations?

V. - Make a careful drawing of a single zooid or hydranth with the tentacles extended. Show these points :-

$a$. The relation of the hydranth to the bell-like projection of the perisarc, which is called the hydrotheca. 
b. The connection of the base of the hydranth to the protop asm in the stem of the perisarc.

c. The shipe of the body, including its basal part, its central part, the tentacles, the proboscis or manubrium ujon the tip of which is the mouth.

VI. - Compare this hydranth with a Hydra. In what respects does it resemble the Hydra? In what respects does it differ from it?

VII. - Study the tentacles carefully, using as high power as necessary. How many are there? Is the number always the same on different hydranths? How does their length compare with the length of the body of the hydranth? See the little nettle cells. How are these arranged?

VIII. - Study the different stages of the young hydranths. Make drawings of two or three of these stages. Are these young hydranths able to get food for themselves? If not, where does the material for their growth come from?

IX. - Trace the connection between a hydranth and the one next above it and next below it on the stem. Is the protoplasm continuous? Can you find any in which a fully developed hydranth with tentacles is next to a partially developed hydranth?

$\mathrm{X}$. - Make a careful drawing of a gonangium, showing the club-shaped perisarc portion and the round or oval bodies inside, as well as the protoplasmic connection with the main stem. The bodies inside are medusabuds. In due time they escape from the club-shaped perisarc into the sea, where thev develop into small, free-swimming jelly-fishes, very different from the hydroid colony. There are thus two sorts of generations of this animal - the fixed colony you have been study- 
ing, and the free-swimming jelly-fish form. For this reason the species is said to have an alternation of generations.

XI. - In what part of the gonangium are the medusa-buds largest?

XII. - Are there any tentacles in connection with the gonangium, or is there any way in which it can get food from outside? If not, where does the substance of which the medusa-buds are built up come from?

\section{MEDUSOID STAGE OF A CAMPANULARIAN HYDROID}

I. - In your study of the hydriform stage of the Campanularian Hydroid you observed, in the gonangia, small bodies called medusa-buds. If you saw well-developed medusa-buds, you found them to be bell-shaped. When mature, these buds break away and escape through the opening in the distal end of the gonangium into the water, where they become at once independent, freeswimming animals.

II. - Compare this free-swimming Medusa to an umbrella with the handle broken off short. The short handle is the manubrium. In its end there is an opening, which is the mouth. From the base of the manubrium to the margin of the circle run four ribs of the umbrella: these are radial canals. They open into a circular canal. Stretching horizontally from the circular canal toward the middle is a thin white membrane: this is the velum. The convex side of the umbrella is called the exumbrella or aboral surface, and the concave side is the subumbrella or oral surface.

III. - Projecting downward from the outer margin of the umbrella are many rather long threads: these are the tentacles. About how many of them are there? 


\section{Branch Cœlenterata}

IV. - Mount one of these tentacles on a glass slide, and observe its structure with the low power. How are the nettle cells arranged along the tentacles? Is there any difference in their arrangement near the basal end of the tentacle and near its distal end? Make a careful drawing of a section from the basal part and of one from the distal part, including in the latter the end of the tentacle.

V. - Now examine the tentacles with the high power. Notice the structure of the nettle cells. Make a drawing showing a bit of the edge of the tentacle with these cells imbedded in it.

VI. - See the wart-like projections along the sides of the radial canals : these are the sexual reproductive organs. In some specimens these produce spermatozoa ; in others they produce eggs. The sexes are therefore distinct. The eggs are fertilized by the spermatozoa which have come from other medusæ. Then each develops into a Campanularian Hydroid.

VII. - Make a careful diagrammatic sketch of a side view of the Medusa, labelling the parts distinctly.

\section{THE TUBULARIAN HYDROID}

HYDRIFORM STAGE

This is an animal living in salt water in rather goodsized colonies. It resembles in many respects the Campanularian Hydroid.

I. - Examine the specimen in your watch glass through a hand lens. Is the branching different from that of the Campanularian Hydroid? Does the colony seem larger? 
II. - Mount a small part of the specimen on a glass slide, and observe it through the low power. Notice that like the Campanularian Hydroid it is composed of two general parts, viz. :-

a. A firm outer covering, the perisarc.

b. An inner protoplasmic part - the living substance. III. - Spread the colony out upon a flat surface and make a sketch of the whole of it. Identify the following divisions of the colony, and label them in your drawing: $a$. The root-like expansion - hydrorhiza - by which the colony is attached to the permanent support.

b. The upright branching stem, the hydrocaulus.

c. The terminations of the branches of the hydrocaulus, without the bell-like expansion of the perisarc which is present in the Campanularian Hydroid.

$d$. The projecting zooids or hydranths on the ends of the terminal branches.

IV. - Examine with the low power an individual zooid. Make a good-sized drawing in which you. show clearly the following parts, labelling them carefully:-

a. The basal connection with the perisarc.

$b$. The ring of long tentacles near the base of the zooid.

c. The ring of short tentacles toward the distal end.

d. The projecting "proboscis" or manubrium on the distal side of the short tentacles.

$e$. The mouth upon the tip of the manubrium.

V. - Study several other hydranths to see what variations exist. Are there always the same number of long tentacles? of short ones?

VI. - Study the tentacles under a higher power. Are there nettle cells present?

VII. - Compare this hydranth with the hydranth of the 
Campanularian. In what respects are the two alike? In what respects are they different?

VIII. - Find two or three hydranths with medusa-buds growing upon the body wall. Make drawings of these, showing different stages of the development.

\section{THE CLASSIFICATION OF THE CCELENTERATA}

The third phylum or branch of the animal kingdom, and the second phylum of the Metazoa, is the Colenterata. This phylum is characterized by individuals having a distinct body cavity with but one external opening, the mouth, and a body wall composed of two layers of cells, the ectoderm and the endoderm. Sometimes a thin or thick layer called the mesoglœa occurs between the other two. The mouth corresponds to the mouth of higher animals, and the body cavity into which the mouth opens corresponds to the alimentary canal of the higher animals. The endoderm of the Cœlenterata is homologous in general with the lining of the alimentary canal, and the ectoderm is homologous with the skin of the higher animals.

The Cœlenterata are universally aquatic animals, occurring most abundantly in salt water. There is generally a row of tentacles around the mouth, the cavities of these tentacles being continuous with the main body cavity ; they aid in the capture of food and in locomotion. Another characteristic feature of the branch is the possession of nettle cells, within each of which is a minute sac containing a fluid and a barbed filament capable of being thrown out for stinging purposes. They reproduce by budding, by fission, and by eggs.

The Coilenterata are divided into four classes, of which the Hydrozoa and the Actinozoa are the most important. The members of the first class, the Hydrozoa, are the most 


\section{Laboratory Guide in Zoology}

typical and easily understood. Their structure is well illustrated by the common Fresh-water Hydra. Members of this class reproduce by budding, sometimes by fission, and sometimes by eggs. Many marine jelly-fishes belong to this class, although a majority of the large jelly-fishes are included in the second class, the Scyphozoa, and a few peculiar forms known as Comb-jellies are included in the Ctenophora, which forms the fourth and highest class of the Colenterata.

The members of the third class, called the Actinozoa, greatly resemble, and were long thought to be, marine plants. Here belong the sea-anemones and other softbodied polyps. The coral polyps, which secrete a kind of calcareous framework, also belong to this class. These animals, living a fixed life, constantly reproducing by fission, have been the chief agency in building up our vast coral reefs and islands. 


\section{CHAPTER IV}

\section{BRANCH TROCHELMINTHES: THE ROTIFER AND ITS ALLIES}

\section{THE ROTIFER, OR WHEEL-ANIMALCULE}

FInd the specimen with the low power: some are likely to be moving about the field too rapidly to be studied; others may be temporarily fixed at the base, and simply moving within an area represented by the length of the body. These are the ones to study. If none such are found, extract the surplus water from beneath the cover glass with a piece of blotting-paper, to quiet some of the active Rotifers. In the study use both the high and low powers of the microscope.

I. - Can you see two different ways of locomotion - one a crawling movement, the other a free-swimming movement? Describe each. Do the Rotifers always go forward when moving? How does the locomotion of the Rotifer compare with that of the Amœba? Is there a distinct differentiation into anterior and posterior parts? Is the movement in a definite direction?

II. - What decided difference can you see between the general structure of this creature and the other microscopic animals (like Paramecium, Stentor, or Stylonychia) you have studied? Is the Rotifer a one-celled animal?

III. - Study and describe the tail-like structure on the posterior end of the body. Does it move from side to side, or disappear within the body, or both? 
IV. - Learn whether the Rotifer revolves frequently on its longitudinal axis. Do you conclude that the animal has a dorsal and a ventral surface?

V. - The cause of the free-swimming movement will be easily made out. Notice that the head appears as if a revolving wheel were attached to its surface: in many species there are two disks showing this motion. This appearance is caused by the rhythmical motion of one or two bands of cilia encircling the disks of the head. These revolving cilia form one means of locomotion. Notice how the contraction of the body affects its movement.

VI. - Study the hard, vase-shaped case into which the extremities of the body are drawn. Observe the degree of its flexibility as the Rotifer moves about. This case is called the lorica; in it are crowded the organs for ingesting, masticating, digesting, and assimilating food, and for egesting waste material; also the organs of reproduction.

VII. - Watch again the head and foot as they are drawn in, and notice that it is then much more difficult to distinguish the parts inside. Observe the Rotifer as it stretches out; you will be able to see narrow bands passing along the body beneath the lorica. Similar bands encircle the body. These two sets form the muscular system of the Rotifer: the movements of the body are due to the contractile power of the muscles.

VIII. - Add a few grains of powdered carmine to the water on the slide. When the particles come near an active Rotifer, see the vortex caused by the movements of the cilia. Watch for the swallowing of some of these grains when the head is suddenly drawn into the body. When two disks of cilia appear, the mouth may be seen 
between them. Distinguish if you can the gullet leading from the mouth, and lined with cilia. The so-called teeth are visible at the inner end of the gullet; behind the teeth lie the stomach and intestine; the latter ends in an opening on the under side of the lorica near its posterior border.

IX. - Make a good-sized drawing of the Rotifer.

\section{THE CLASSIFICATION OF THE ROTIFERS AND THEIR ALLIES}

Early in the history of zoological science the Rotifers were classified with the Infusoria. But as soon as it was seen that they were multicellular animals, it was necessary to remove them from the branch Protozoa and to find for them another resting-place in the system of classification. No place seemed more fitting than the branch Vermes, which was formerly made to include the worms and various related creatures. It has long been recognized, however, that the Vermes was too heterogeneous a collection to satisfy the requirements of our knowledge, so that the latest authorities have divided it into several groups, each with the rank of a branch or phylum. The Rotifers, and two other less abundant classes of minute animals somewhat resembling the Rotifers, have been united to form the phylum Trochelminthes. The young of these creatures exist in the form of a trochosphere, which becomes modified during the development of the animal. The class Rotifera is much the most important one in this phylum.

Four other groups have been separated from the Vermes and raised to the rank of independent phyla. One of these, the Annulata, is considerably higher than the rest and is discussed later in this book in connection with the earthworm. 
The lowest of these branches into which the old group Vermes has been broken up, is the branch Platyhelminthes, which includes the so-called Flatworms. These are soft-bodied, bilaterally symmetrical animals in which the body is generally compressed above and below so as to give a flattened appearance. There is not a distinct body cavity. This group includes many species, some of which live free in water of ponds and streams, while others are parasites; the tapeworm of man is an example of the latter.

The next higher branch is called the Nemathelminthes, and includes the so-called Roundworms or Threadworms, the "Hook-headed worms," and the "Arrow-worms." In general the body is cylindrical. The most important class is the Nematoda, which includes the "vinegar eels" and various small worms that live as parasites in the roots of plants, as well as the Trichina spiralis found in pork and often causing disease in man.

The third group which has been separated from the Vermes is the Trochelminthes already discussed, while the fourth is the Molluscoida. This is composed of three classes ; namely :-

I. Polyzoa. The "Sea-Mats" and "Corallines."

II. Phoronida. Phoronis, a worm-like animal living in the sea.

III. Brachiopoda. The Lamp-shells. 


\section{- $\quad$ CHAPTER $・ \mathrm{~V}$}

\section{BRANCH ECHINODERMATA: THE STARFISHES AND SEA- URCHINS}

\section{THE STARFISH}

StaRfishes furnish excellent objects for study, whether freshly killed or preserved in alcohol or formalin. The internal structure is best made out by dissecting under water. Of course the larger the specimens are the more satisfactory will be the results. Dried specimens are desirable for the study of the outer surface.

\section{EXTERNAL ANATOMY}

I. - What gives the animal its star-like appearance? Distinguish the flat ventral surface from the more rounded dorsal surface. To understand that the body is pentagonal-shaped, imagine the rays cut off at their bases.

II. - Compare the animal's symmetry with that of the frog. Notice the apparent absence of anterior and posterior ends. Such an arrangement may be called radial symmetry. The following method, however, will enable you to understand that the arrangement of parts approaches a bilateral symmetry, or such an arrangement of parts that the whole may be divided into two similar halves: Find a smooth circular white, yellow, or orange spot - the madreporite - near one side of the dorsal disk and near the angle formed by two adjacent rays. Will an imaginary line drawn from the madreporite across the starfish divide it into two similar parts? 


\section{Laboratory Guide in Zoology}

III. - With a pocket lens observe quite carefully the appearance of the rough dorsal and lateral surfaces. Find as many kinds of projections as you can. The hardpointed projections, or spines, are developments of the body wall, and are used for purposes of protection. Around the bases of the spines are the forceps-like pedicellariæ.

IV. - The soft blunt projections are hollow processes of the body wall. They allow the fluid of the body cavity visceral fluid - to come into contact with the external water and air, and are called papulæ or respiratory cœca.

V. - Find a small anal opening, lying near the centre of the dorsal disk on a line drawn from the centre of the disk to the angle formed by two rays.

VI. - Place the animal upon its back, and observe its ventral surface. Notice the five grooves, one in each ray, terminating internally at the side of a pentagonalshaped depression. Because these grooves contain organs of locomotion they are called ambulacral grooves.

VII. - Notice that beneath this pentagonal-shaped depression a colorless membrane with a small opening in its centre is stretched. This is the peristome, and the opening in the peristome is the mouth. The peristome is connected with the wall of the alimentary canal.

VIII. - Observe the kind of organs that fill the ambulacral groove. They are short, cylindrical structures called ambulacra or tube feet. How many rows in each groove? The tube feet are a part of quite a complicated system which serves the function of locomotion and possibly of respiration.

IX. - With the forceps, push aside the two inner rows of tube feet, so that you can look down into the very roof 
of the groove. See if you can find there a small, white thread-like structure - a nerve trunk - sending out branches to the feet. Follow this to the end of the ray, where it ends in the midst of a little bunch of spines. Look at this bunch of spines carefully with a pocket lens. Examine the termination of each ray in this way. Is there any connection of the nerve trunk with the red spot at the end of the arm? This spot is sensitive to light, and for that reason is called the eyespot. Follow the nerve trunk to its inner termination at the base of the ray. Is it connected with the circular nerve ring, surrounding the peristome and the mouth?

\section{INTERNAL ANATOMY}

X. - With sharp-pointed scissors, remove the integument from the dorsal surface of one of the rays, being very careful not to disturb any of the underlying parts. Remove also the body wall from the main dorsal surface, leaving the madreporite untouched. Be especially careful to harm none of the internal organs when removing this part of the body wall.

XI. - Observe the following structure: Two long pointed, brown, lobulated bodies lie side by side, nearly filling the ray from base to tip. These are digestive glands (that is, organs the cells of which secrete a digestive fluid); they are called hepatic cœca.

XII. - Notice the colorless ducts running along the centre of these masses, uniting near the bases of the ray. Follow up this common duct, and see that it empties into a flat, membranous, pentagonal-shaped sac, a part of the stomach called the pyloric sac. Below this is the stomach proper, with which the pyloric sac is continuous. 
XIII. - Above the pyloric sac is the intestine, but on account of its small size it was probably torn away with the body wall. Make out a similar connection between the pyloric sac and the digestive glands in the other rays.

XIV. - Upon the surface now exposed, muscles were arranged which lifted the rays and moved them from side to side. They were probably cut away when the integument was removed. Try to find parts of them extending from the centre of the body along the median line of each ray.

XV. - Turn back both hepatic cœca and observe the stomach carefully. Notice its large, blunt projection, the cardiac pouch, extending into each ray a short distance. Push this carefully aside, and see the narrower part below, corresponding to an œsophagus or gullet, into which the mouth opens.

XVI. - On each side of the ray, at its very base, and attached to the walls separating that ray from the adjacent rays, find two small white or orange colored lobed bodies, shaped something like a single digestive gland: these are the reproductive bodies. At the place of attachment, there is an opening in the body wall for the passage of the contents. See if there are two, similarly placed, in each of the other rays. These organs are either ovaries or testes; that is, the sexes are separate. The eggs are fertilized, and the development of the young starfish takes place outside of the body.

XVII. - You will notice a very interesting arrangement of the parts now exposed on the floor of the ray. Keep the specimen constantly under water. See four rows of colorless, inflated, closed tubes: they resemble in arrangement the tube feet just below them on the 
under side of the ray. These structures are called ampullæ (a single one is called an ampulla), and are directly connected with the tube feet. In fact, an ampulla is an enlarged extension of a tube foot. At the junction of the ampulla and the tube foot, there is a short tube connecting them with a long one which passes close to the nerve trunk along the roof of the ambulacral groove.

This long tube passes the entire length of the ray, and connects with a pentagonal, or rather circular, tube around the peristome. Carefully push aside the parts lying beneath the madreporite, and you will see a long, hard, white tube extending downward. This is called the stone canal. Does it connect with the circular tube just mentioned? The madreporite is very finely perforated, and through these openings water passes down the stone canal, filling the circular tube. From the circular tube the water passes along the radial tubes in the arms, and from them into the short branch tubes leading to the ampullæ and tube feet. The whole system is called the water-vascular system. A patient study is required to understand well the arrangements of parts in this system.

XVIII. - Learn how locomotion is performed by the watervascular system. As has been said, the system is filled with water through the pores of the madreporite. Water is forced from the ampullæ into the tube feet, throwing them forward. The contracting walls of the tube feet then force the water back into the ampullæ, and suction makes the feet stick to the surface upon which they were lying. The body may be then drawn forward and the operation of extending the feet repeated. From what you know of the animal's mode 
of locomotion, would you say that it possesses anterior and posterior parts?

XIX. - The blood system you will probably be unable to make out. It has the same general arrangement as the nervous and water systems, that is, a circular ring around the peristome, which sends out five branches of vessels, one to each ray.

$\mathrm{XX}$. - Dissect each of the remaining rays, varying the operation to suit the necessity of clearing up any points not at first understood. Make drawings.

\section{THE SEA-URCHIN}

The Sea-urchin lives along the seacoast, and may often be found abundantly in pools among the rocks when the tide is out. Two species are common along the Atlantic coast.

I. - Notice the general appearance of the animal - the spheroidal shape of the body, and the spines with which it is covered. See that one side is more flattened than the other; this is the oral surface, while the other is the aboral surface.

II. - Examine the oral surface carefully. See the central mouth opening, with its five projecting calcareous teeth, and the more or less membranous area surrounding it; this area is the peristome. See whether that part of the peristome next to the mouth opening is thickened. Find also the small calcareous ossicles which give strength to the membranous peristome. Make a drawing of the peristome and mouth.

III. - Find along the outer margin of the peristome a great many of the movable ambulacra or tube feet, each ending in a sucker-like disk. Each of the ambulacra consists of a cylindrical basal portion, which in the living 


\section{Branch Echinodermata}

animal can be greatly lengthened, and the disk-like tip by means of which it holds on to objects. Make a drawing showing the structure of the sucker-like tip. The flat central disk is supported by a calcareous plate. IV. - In addition to the numerous ambulacra on the outer margin of the peristome, find five pairs with somewhat larger tips surrounding the mouth. See between the pairs of ambulacra the groups of pedicellariæ, appearing as miniature forceps on slender stalks. Are these present on other parts of the body?

V. - Find other ambulacra among the spines over the rest of the body. How generally are they distributed?

VI. - Extract at its base one of the long spines with which the body is covered. Study it with a hand lens and make a careful drawing showing the following parts :a. The basal piece extracted from the body wall.

b. The membranous part by which the spine is attached.

c. The long spine proper, with its tapering surface fluted longitudinally.

$d$. The flattened tip, with its polished tooth-like surface.

VII. - Dissect out the flexible basal part of the spine to see the ball and socket joint. Make a diagrammatic sketch showing the structure accurately.

VIII. - Describe the arrangement of the spines with reference to the mouth, noting especially the differences in the length and the structure of the tips.

IX. - Make a careful drawing of the spineless aboral area on the side opposite from the mouth. Show the four anal plates; these form the periproct.

$\mathrm{X}$. - Study now a specimen on which the spines and soft parts have been removed by soaking for a few days in a strong solution of caustic potash. On the aboral sur- 
face notice the space formerly occupied by the periproct. Notice that around it are five genital plates, each having a small hole near the apex; these are the reproductive openings. See that one of the plates is larger than the others and is full of minute perforations; this is the madreporic body. Make a drawing of the aboral surface of this specimen.

XI. - Study the oral surface of the same specimen. Notice the large opening formerly occupied by the peristome. What shape is it? Notice the five interradial sutures from the tip of each genital plate to the corresponding angle of the mouth pentagon. See the double rows of polished prominences for the attachment of the spines. See also the zigzag ambulacral suture running between each double row, and the double rows of ambulacral pores on each side of the double rows of spines.

\section{THE SEA-CUCUMBER}

The Holothurians or Sea-cucumbers are strange creatures that live in the ocean. They form a separate class (Holothuroidea) of the great group to which the starfish and sea-urchin belong. They have a water-vascular system similar in general to that of the starfish.

I. - Make a drawing showing the general shape of the body and the position of the tentacles, as well as of the mouth and of the anal opening.

II. - Describe the number, size, shape, and position of the tentacles.

III. - Examine with a hand lens the ambulacral suckers with which the body is covered. Make a drawing of one of these, considerably magnified. Are these more abundant on the lower side of the animal? On the upper side, are they more abundant near each end than in the 
middle of the body ? Can you see that these ambulacral suckers are arranged in five broad bands?

IV. - Cut the body wall longitudinally on one side to lay open the central cavity. See the long much-coiled alimentary canal. Notice the structure of this canal; next the mouth is an œsophagus ; below this is a well-defined stomach; next comes the long, convoluted intestine, which is small in size throughout until it opens into the larger cloaca, at the posterior end. Make a sketch of the alimentary canal, labelling each part.

V. - Remove the intestine, leaving the other parts of the canal intact. The most noticeable objects now visible are the genital gland, the respiratory tree, and the five sets of longitudinal muscles.

VI. - The genital gland is near the middle of the upper half of the body cavity. It looks like a sort of brush, being composed of many slender filaments lying side by side. Notice that the duct leading from these extends to an opening between two of the tentacles. (The genital gland may be the ovary or the testes, as the sexes are separate.)

VII. - Trace out the two main divisions of the respiratory tree with their many branches. Notice the connection of each half with the cloaca. In this way fresh sea water reaches them.

VIII. - Study the five sets of longitudinal muscles, extending up and down the body walls. Trace these out carefully and describe them. Notice also the circular fibres which strengthen the body wall. 


\section{THE CLASSIFICATION OF THE ECHINODERMATA}

The starfish is perhaps the most typical representative of the branch Echinodermata, which includes also the seaurchins, the sea-slugs or sea-cucumbers, the sea-lilies or feather-stars and the brittle-stars. In the members of this phylum the arrangement of the parts in a circle around a common centre is the most striking general character. This is obvious in the starfish, and may easily be seen in the other members of the group. There is also a calcareous outer skeleton which varies much in its texture, but the frequency with which it is furnished with spiny projections led to the name Echinodermata. All members of the phylum live only in salt water. There are two openings to the alimentary canal. There is also a distinct nervous system, a circulatory system, a water system for locomotion, and other complicated organs.

There are five principal classes of the Echinodermata, namely :-

I. - Asteroidea. The starfishes are the typical representatives of this class. They abound in almost every sea, and may be found partly buried in the sand or concealed beneath the shelter of the rocks. As the name implies, they are star-shaped, generally with five rays. In color they vary considerably, but they are commonly some shade of yellow, orange, or red.

II. - Ophiuroidea. This class is made up of the peculiar sand-stars and brittle-stars, which have the arms longer and more distinctly separated from the central portion of the body than do the starfishes.

III. - Echinoidea. The spiny sea-urchins form this group. In these the arms are absent, the body being rounded, 


\section{Branch Echinodermata}

and covered with a shell made up of closely united plates of a calcareous nature, to which stiff spines are attached. Sea-urchins live in rocky holes and crevices along the borders of the ocean, where they feed upon molluscs and seaweeds. Their mode of locomotion is similar to that of the starfish, although the movement is much slower.

IV. - Holothuroidea. The strange sea-cucumbers or seaslugs belong to this class. In these the body is elongated and covered with a thickened leathery wall. Around the mouth is a ring of tentacles. These sluggish creatures live in the ocean, especially in tropical regions.

V. - Crinoidea. The members of this class are commonly known as feather-stars or sea-lilies. They are comparatively few in number, and for the most part being fixed to the bottom of the sea, they are seldom found. The star-shaped body is usually attached to a stalk. In former geologic times crinoids were very abundant; the formation of vast limestone areas is attributed to the gradual accumulation of their remains. 


\section{CHAPTER VI}

\section{BRANCH ANNULATA: THE TRUE WORMS}

\section{THE EARTHWORM}

For the purposes of this study both living and dead earthworms should be provided. The larger the specimens, the more satisfactory will be the results. Kill some of the worms by enclosing them in a covered dish containing a little ether or chloroform. If the internal anatomy is to be studied in such freshly killed specimens, they should be dissected under water in a shallow dish having the bottom covered with wax or sheet cork. The internal anatomy may also be studied in specimens hardened in alcohol, although some of the more delicate parts are likely not to show so well as they do in fresh specimens.

\section{MOVEMENTS AND EXTERNAL ANATOMY}

I. - Place a living earthworm on a sheet of paper. Watch its movements. Determine which is the anterior end and which the ventral surface. Is it able to move backwards? By what means does it move? Is there a decrease in diameter when the worm stretches out?

II. - Find the bristle-like setæ on the ventral surface. How many rows of them are there? Toward which end of the body do the tips of the setæ point?

III. - Notice how the earthworm is divided into narrow rings, or segments, throughout its length. Study the first segment; the lip-like projection above the mouth is called the prostomium. 
IV. - A few segments back of the head find a ring-like swelling of the body: this is the clitellum. It is more prominent in some specimens than in others.

V. - Examine the external surface carefully for openings through the skin. The mouth and anal openings are easily found. Find a small pore in the grooves between successive segments behind the tenth along the middorsal line; these communicate with the body cavity and will sometimes emit a milky fluid when the animal is irritated. On the ventral side of the fourteenth segment find two small openings, the external terminations of ducts leading from the ovaries. The external openings leading to the seminal vesicles will be found in the fifteenth segment. Draw a side-view of the earthworm.

\section{INTERNAL ANATOMY}

VI. - Pin the specimen to the bottom of the dissecting dish with its ventral surface downward, by inserting one pin through the prostomium and another through the posterior segment, stretching the body a little. With sharp-pointed scissors cut through the very thin body wall, near to and parallel with the dorsal median line. Be careful not to cut too deep. Notice the many transverse partitions joined to the inner surface of the body wall. Determine whether they correspond to the constrictions between the segments. Cut these partitions carefully down each side close to the body wall, and pin down the flaps of skin thus laid open.

II. - The alimentary canal is now exposed. Notice that it passes directly through the partitions between the segments. See the dorsal blood-vessel along the top of the alimentary canal. Near the eighth and ninth segments, find branches running from this dorsal blood- 
vessel around the alimentary canal to join the longitudinal ventral blood-vessel. These aortic arches form the centres of the blood system.

VIII. - The most conspicuous bodies now exposed are the white-lobed seminal vesicles in the tenth and eleventh segments. They are connected by ducts with external openings on the ventral surface of the fifteenth segment.

IX. - The alimentary canal is composed of five parts, named as follows, beginning at the anterior end: pharynx, œsophagus, crop, gizzard, and intestine. Distinguish each. The pharynx is continuous with the mouth and has light-colored muscular walls; it extends to about the seventh segment. The œsophagus is a straight tube, generally extending from the eighth to the sixteenth segments. Near the sixteenth segment the alimentary canal is enlarged, forming a sort of thinwalled pouch; this is the crop. Directly back of it is the muscular gizzard. The rest of the canal forms the intestine. Make a drawing of the canal.

X. - Over the pharynx, near the anterior end, find two small white oval bodies, which form the central part of the nervous system : they are the cerebral ganglia. Remove the intestine carefully, and find a white ventral nerve cord extending longitudinally.

XI. - The ventral blood-vessel will be found extending longitudinally below the alimentary canal. It may be necessary to use another specimen in order to demonstrate it.

XII. - Carefully push aside the alimentary canal from about the eighth to about the fourteenth segment. The very small white bodies to be seen in the base of the thirteenth segment are the cvaries. Near these are two 
short funnel-shaped tubes, the oviducts, which pass through the partition to the fourteenth segment, and thence through the body wall to the outside. These furnish an exit for the contents of the ovaries.

XIII. - Between the ninth and tenth, and between the tenth and eleventh segments, find two pairs of white pearshaped bodies; these are the seminal receptacles.

XIV. - Beginning with about the fourth segment, find in the base of each segment except the last, and attached to the posterior surface of the septum in front, long, somewhat coiled, tubular organs. One end is free, but terminates in the nextanterior segment by passing directly through the partition: the other end communicates with the exterior. These are excretory organs called nephridia. They are brought out distinctly by blowing alcohol upon them through the tube of a wash bottle.

\section{THE MARINE ANNELID}

\section{(NEREIS VIRENS)}

This curious worm lives in the mud along the seashore and the bottoms of tide marshes. It is of special interest because it shows a more highly differentiated structure than does the earthworm.

I. - Study and describe the general shape of the body. What are the most important ways in which it differs from the earthworm? How many segments are there? II. - How do the appendages along the sides of the body compare with the segments in number? Is it easier to distinguish the anterior and posterior ends than in the earthworm?

III. - Study the head: it has no appendages that project laterally from the sides, and is divided into two general 
parts - a small anterior part, the prostomium, a large posterior part, the peristomium. Make careful drawings of the upper and lower views of the head and the first three segments back of it.

IV. - Study the prostomium. Is it distinctly differentiated from the peristomium? Notice the central lobe bearing in front the two club-shaped tentacles. Are they segmented? See on each side of this central lobe the large conical palpi, distinctly segmented. Find the small black spots which are the eyes. How many are there?

V. - Study the peristomium : on each side in front are the two cirri, each double: Find the mouth. Sometimes this is extended and shows the two black, serrated mandibles.

VI. - Study the lateral appendages of the body segments, - they are the parapodia. Are they of the same size throughout the length of the animal? Remove with forceps one of the parapodia, and examine it with a low magnifying power - a simple lens will do. Distinguish two general parts - the dorsal and ventral lobes. On which is a large subtriangular blade - the gill? Which bears the most spinose setæ? Treat a parapodium with caustic potash solution to bring out the spinose acicula. Make a careful drawing of a parapodium showing its parts and its basal connections.

VII. - Lay the worm on the bottom of the dissecting tray, ventral side down. Cut longitudinally along the median dorsal line, and pin down the cut edges on each side. See how the body cavity is segmented.

VIII. - Study the alimentary canal: see how the mouth opens into the pharynx, which in the living worm can be protruded; and how the pharynx leads into the 
œsophagus, and the latter into the long intestine which extends to the posterior end. Can you see a small gland on each side of the œsophagus? Where do these glands empty? Do the constrictions of the intestines correspond to the divisions of the segments? Notice the mesentery below the intestines, binding it to the body wall. The mesentery of the upper part was probably destroyed when the body was cut open.

IX. - Cut open the pharynx: notice the powerful muscles and the two conspicuous black teeth which may be seen on the outside in those specimens in which the pharynx is protruded.

$\mathrm{X}$. - Trace out as well as you can the blood-vessels and the nerve system. 


\section{THE CLASSIFICATION OF THE ANNULATA}

The earthworm is a typical representative of the phylum Annulata, nearly all the members of which have an elongate body divided into numerous segments, with an internal partition between each of the segments. There is a welldeveloped alimentary canal, a distinct body cavity, a system of blood-vessels, and a nervous system with cerebral ganglia and ventral nerve cord which is double, and generally shows a series of ganglia along the segments. The members of the phylum also have nephridia, or pairs of tubes leading from the body cavity through the body wall and serving as organs of excretion.

This phylum is divided into four classes, namely:-

Class I. Chætopoda. The Earthworm and Nereis.

Class II. Gephyrea.

Class III. Archi-annelida. Polygordius and its Allies.

Class IV. Hirudinea. The Leeches.

Of these four classes the first and fourth contain the most generally known members of the branch. The second class, Gephyrea, is exceptional in its characters, in that the members of it are not segmented when adult, although they show the segmented condition during their development. 


\section{CHAPTER VII}

\section{BRANCH ARTHROPODA: ANIMALS WITH JOINTED LEGS}

\section{THE WOOD-LOUSE OR SOW-BUG}

THESE curious creatures may be obtained in abundance under boards and stones, especially in moist situations. For this study, get as large specimens as you can find.

I. - Notice the segmented character of the body. See if you can easily distinguish the three divisions of the body - head, thorax, and abdomen.

II. - When the animal is viewed from above, the head is what appears to be the first segment. Determine the limits of the head by looking at it from both sides. Notice its mode of attachment to the first segment of the thorax.

III. - To distinguish between the thorax and abdomen, look for a place where there is a decided difference in the size of two adjoining segments as seen from above. How many segments has the thorax? How many has the abdomen?

IV. - Returning now to the head, study the long, jointed antennæ. Compare the segments of these with the segments of the legs. Is there a similarity? Notice the aggregation of simple eyes near the base of each antenna.

Unless the specimens are quite large, the mouth parts are not easily distinguished by beginners. The jaws, maxillæ, and upper and lower lips come close together in a point. The tips of the jaws are black. 
V. - How many legs has each segment of the thorax? Make a drawing of one of the legs as it appears under the lens, showing distinctly in the drawing the parts of which it is composed. In female specimens, there is a thin membrane or covering - the egg pouch - on the ventral surface of the thorax at the bases of the legs.

VI. - Study the plate-like gills on the ventral surface of the abdomen. Why should these creatures be found only in moist situations?

\section{THE LOBSTER, OR CRAYFISH}

The lobster is one of the most satisfactory animals to study. It is better to have fresh specimens that have not been boiled, but if these are not easily obtainable, boiled specimens may be substituted. In regions where crayfishes are abundant, these may be used instead of the lobster.

\section{EXTERNAL ANATOMY}

I. - Does the lobster show a more marked bilateral symmetry than the earthworm? Study the hard, strong covering of the body; this is a true outer skeleton or exoskeleton. Notice the soft, pliable places in the skeleton which permit the bending of the body. These places differ from the rest of the skeleton only in having no calcium.

II. - Axial Arrangement. In the axial arrangement of parts what resemblances can you find between the earthworm and the lobster? Both have a ringed or segmented structure, but in the lobster this is shown only in the posterior part of the body. Notice that the body axis is separated into two great divisions. The anterior one includes the head and thorax, closely united, and is called the cephalothorax. The posterior 
division comprises the remaining part of the animal, and is called the abdomen. Fix carefully in mind the precise boundary of these two great divisions, by bending the abdomen back and forth to see its mode of union with the cephalothorax. The broad, unsegmented covering of the cephalothorax is the carapace, and its toothed projection between the eyes is the rostrum. Near the middle of the carapace find a distinct transverse suture ; this represents a somewhat indistinct division between the head and thorax, and for that reason is called the cervical suture.

III. - Abdominal Somites. Find the seven distinct ringlike segments, or somites, that form the abdomen. In any single somite distinguish the following parts: (I) The broad, dorsal part is the tergite. (2) The narrow, ventral part of the ring is the sternite. (3) The pointed, somewhat curved part which forms each side is the pleurite. Notice how the seventh, or the last, segment, the telson, differs from the others.

IV. - Abdominal Appendages. On the sternite of each segment find a pair of jointed movable organs, the swimmerets. Examine a single one of these, and find that it is made up of a basal part, the protopodite and two branches; the outer branch is the exopodite and the inner branch is the endopodite. Examine other swimmerets to confirm this structure. Those of the first and second abdominal segments are usually modified, and in the female are sometimes wanting. The swimmerets of the sixth segment are so much enlarged, and so like the hard parts of the skeleton, that they will not at first be recognized as swimmerets. The exopodites and endopodites of these swimmerets together with the telson form the tail fin of the lobster. 
V. - Somites of the Cephalothorax. From a ventral view notice how small are the sternites of the thoracic segments. This is caused by the enlargement of the basal joints of the appendages. The unbroken sides of the carapace represent the united pleurites of the various thoracic somites. Follow carefully the irregular outline of the carapace, and indications of the segmented structure will be seen. In general it may be said that each pair of limbs on the cephalothorax represents a single somite.

VI. - Appendages of the Cephalothorax. Study carefully the following parts:-

$a$. The four posterior, nearly uniform, appendages are the legs used for walking.

b. The much larger pair, just anterior to these, are used for capturing and crushing food, and are called chelæ.

c. Directly in front of the chelæ find three pairs of appendages drawn closely to the body. These are of the nature of legs, but since they serve to prepare the food for the mouth, they are called maxillipeds.

$d$. The two appendages directly anterior to the maxillipeds are the true maxillæ. Notice the scoop-like structure held by the second maxilla: it is called the gill scoop.

e. In front of, and beneath the maxillæ, are the hardtoothed jaws, or mandibles. Move them back and forth to see their mode of action. Is it from side to side, or up and down?

$f$. The long tapering structures with large basal segments are the antennæ: they serve as organs of touch.

$g$. The somewhat similar, but two-branched and shorter, 


\section{Branch Arthropoda}

pair directly in front of the antennæ are the antennules, serving the same function as the antennæ and probably that of smell. Each also contains in its basal part an organ of equilibration.

h. The jointless stalks protruding from either side of the rostrum are the eye-stalks, tipped with the eyes. Examine them to learn the field of vision possessed by the lobster.

VII. - Breathing Apparatus. With strong scissors remove one side of the carapace. The light-colored, manylobed organs thus exposed are the gills, or breathing apparatus of the lobster. They are bathed in the water that flows under the overhanging carapace. Move the legs back and forth, and see the relation between the legs and gills. Move the maxilla to which the gillscoop is attached, and observe how a stream of water may thus be made to pass under the carapace. The blood passes through the gills, thus coming into very close contact with the water, to which it gives up its carbonic acid and from which it receives its oxygen. VIII. - External Openings. Find the mouth, tightly covered by the mandibles and maxillæ. On the ventral side of the telson, find a short longitudinal slit, the anal opening. Examine the basal segments of the third and fifth legs, to find the small external openings of the reproductive organs. Those of the female will be found in the basal segments of the third pair, and those of the male in the basal segments of the fifth pair. But one kind of reproductive organs will be found in an individual. Compare this with the case of the earthworm. On the basal segment of each of the antennæ find a single small opening, the outlet of the excretory organs. On the upper surface of the basal segment 
of each of the antennules find a peculiar structure, the organ of equilibration.

IX. - Comparison of Appendages. Remove one of the chelæ, study and number its parts. Remove, study in the same way, and compare with the chelæ, one of the first or second walking legs. Go through the same process with one of the fourth walking legs. Review the entire row of appendages, and note that all are in pairs, and that they are nearly all jointed, and possess branched terminations. Regarding each pair of appendages as representing a single somite, determine the number of somites of which the lobster may be said to be made up. Draw a side view of the animal.

INTERNAL ANATOMY

X. - Muscular System. Remove, with strong knife or scissors, the tergites of the abdominal segments, cutting away the muscles attached to them. The white masses filling the abdomen are the strong muscles, and form the edible flesh of the lobster.

XI. - Blood System. Remove in a similar manner the entire top of the carapace, being very careful to disturb none of the organs below. Near the centre of the thorax, find exposed a soft, plastic, somewhat angular body, the heart. Find the colorless, hence somewhat indistinct, arteries, running forward, laterally, and backward from the heart. Follow the artery running backward, by pushing aside the muscles between which it lies, and observe its branches supplying the surrounding tissues. The straight tube below, and attached to the blood-vessel, is the intestine.

XII. - Reproductive System. Carefully remove the heart, and find directly below it either the testes or the ova- 
ries. The testes are a pair of three-lobed bodies, generally white. If testes are present, find the ducts leading from them to the external openings which have already been found. The ovaries are a pair of long, two-lobed bodies. If these are present, find their ducts. Remember that only ovaries or testes will be found in an individual, never both.

XIII. - Digestive System. Remove the reproductive organs, and the most conspicuous portion now exposed will be the digestive glands. Find the ducts by which their contents are emptied into the small intestine. The stomach is the hard-walled receptacle just in front of these glands. It passes anteriorly into the œsophagus, and posteriorly into the small intestine. Pass the forceps through the mouth into the œsophagus, and watch its passage to the stomach. The very short small intestine expands into the large intestine which terminates in the anal opening in the telson. Remove the stomach and open it, to find an apparatus for crushing the food. Make a sketch of the digestive system.

XIV. - Nervous System. Beginning with the posterior part of the abdomen, carefully remove the body muscles from the abdomen and thorax. Left plainly exposed between the muscles will be found the nerve cord with its branches. Follow that forward to the head. In the thorax it enters a hardened passage, to remove which will require some care. Just posterior to the œesophagus, find a large ganglion into which the nerve passes. Find a similar ganglion in front of the œesophagus. You may be able to see how these are connected by the nerve cord passing around the œsophagus. 
The fact that the digestive canal passes at its anterior end through a ring of the nervous system is an important characteristic of animals below the vertebrates, or back-boned animals. Find, if you can, nerves passing from the forward ganglion to the eyes, antennæ, and antennules. Make a sketch of the nerve system.

XV. - Excretory Organs. Directly under the antennæ, see the green bodies, the excretory glands, whose openings are found in the basal segments of the antennæ.

XVI. - Compare the structural plan of the lobster with that of the earthworm, remembering that both are analogous to a tube within a tube, the edges of both tubes being united at both ends. With this structure in mind, tell which tube the mouth and the anal opening are connected with. In which tube do the reproductive and excretory organs lie? Where do their ducts lead? In which tube does the liver lie, and into which do its ducts pass? What is the relation of the skeleton and body muscles to the system of tubes?

\section{THE COMMON CRAB}

Crabs are familiar to all who have wandered along the sea-shore at low tide. They run sideways over the exposed rocks, or crawl leisurely along the bottoms of the pools. They are closely related to the lobster, although very different in appearance.

I. - Study the body as to its general shape. What modifications in the size, shape, and arrangement of the cephalothorax and abdomen make it appear so different from the lobster? Where is the abdomen situated? Draw the view presented as you look down upon the back. 
II. - Study the carapace. Is its front margin denticulate.? Are there any sutures? Distinguish these parts, which are marked off by the sutures:-

a. The gastric lobe, a large, elevated, subtriangular area in the middle of the front half.

b. The cardiac lobe, a somewhat similar area, back of the gastric lobe.

c. The hepatic lobes, one on each side of these median lobes.

III. - Study the ventral surface; make a drawing of it. See the large plastron which forms the under side of the body. Notice the plates of which it is composed. Notice the broad groove in which the abdomen rests. In male specimens the abdomen is narrow; in female it is broad and rounded, its concave ventral surface forming a chamber in which the eggs may be carried. How many segments in the abdomen?

IV. - Study the six pairs of appendages attached to the sides of the plastron. Beginning posteriorly, find four pairs of walking legs, one pair of large chelæ, and one pair - the third - of maxillipeds. Are the appendages similar in general structure to those of the lobster? Study the appendages of the head.

V. - Immediately in front of the third pair of maxillipeds are the second and first pairs of maxillipeds. In front of the latter are the large mandibles. Find the eyes. How are they situated? Find the antennules and the antennæ.

VI. - Find a large orifice on each side of the head, opening into the branchial chamber. Notice a membranous flap on each side. See if this is a part of the second maxilliped.

VII. - Should you say that the crab is to be placed higher 
in the scale of classification than the lobster? Does it show greater differentiation in its structure?

\section{THE CYCLOPS}

The Cyclops is a microscopic crustacean of the same class to which the lobster belongs. It may be found in the water of almost any aquarium where aquatic plants have been growing; it appears to the naked eye as a small white speck swimming rapidly about with a peculiar, jerky movement. The large specimens usually found are females. The males are much smaller, and generally are less abundant, and therefore are not so well adapted to study. Preparatory to a study with a low power, several specimens should be removed from the culture jar to a watch glass. To do this, place a finger on the end of a short glass tube, and inserting the other end in the water as near the specimen as possible, remove the finger; the animals will be drawn into the tube with the surrounding water, and by again covering the exposed end of the tube they may be transferred to a watch glass. If a little ether is placed in the water containing the animals, their rapid actions will be checked, giving a better opportunity for observation. Place the watch glass on the stand of the microscope and study with the low power.

I. - Dorsal View. By careful manipulation, find a specimen showing a good dorsal view. Observe the oval body, tapering rapidly toward the posterior end. Study the segmentation of the body axis; since the head and thorax are united, as in the lobster, the body axis may be divided into the two great divisions, - the cephalothorax and abdomen. The cephalothorax is composed of the first five segments beginning with the anterior 
end. The remaining tapering segments make up the abdomen. Observe the broad dome-shaped carapace making up the anterior part of the cephalothorax. Compare this with the carapace of the lobster in position and shape. If the specimen is a female, a pair of egg sacs may be seen attached to the first abdominal segment. Study the greatly developed posterior segment of the abdomen, with its branched projections. Observe the yellow outline of the intestine showing through the wall of the abdomen. Dark masses showing through the carapace are the reproductive organs. Near the anterior edge of the carapace on the median line, find the dark purple eye-spot : this is really made up of two disks which may be seen with the high power.

II. - Lateral or Ventral View. Obtain a good lateral or ventral view, if necessary using the needles in manipulation. The most noticeable appendages of the cephalothorax are the long-jointed antennæ. Just back of these another smaller pair, the antennules, may be found. Just below the two pairs of antennæe the mouth parts surrounding the mouth are grouped, although it may be quite difficult to distinguish clearly the pair of mandibles and the two pairs of maxillæ. At some distance behind the mouth parts are the four pairs of thoracic appendages, the legs. Study the segmentation of the legs, and try to make out a fifth, rudimentary pair. 


\section{THE FLATTENED CENTIPEDE, OR THOUSAND-LEGS}

The common "thousand-legs," or centipedes, are found under boards and logs. For this study those with flattened bodies should be selected.

I. - Observe the jointed nature of the body. See that the head is easily distinguishable. Is there any distinct division between thorax and abdomen? From a dorsal view, count the segments back of the head. Are all the segments of the same size?

II. - Count the pairs of legs. Does each segment bear one or two pairs? Study the legs carefully. Are they jointed? If so, how many segments has each?

III. - Find the breathing pores, or spiracles : one on each side of a segment, just above the coxa, the first legjoint.

IV. - Examine the antennæ - the most noticeable appendages of the head. Directly behind the antennæ find the eyes - blackish clusters made up of many ocelli, or single eyes, crowded near together.

V. - Directly in front of the base of the antennæ, find two pairs of mouth parts, or jaws, one pair being much smaller than the other. But first distinguish carefully the front pair of legs, so much modified that they look like sharp claws. In poisonous species the poison is secreted in these claws.

VI. - Make a good-sized sketch of the centipede as seen from the dorsal side, and another of the head as seen from the ventral side. 


\section{THE LOCUST, OR GRASSHOPPER}

Collect as large specimens as you can find. Have the dead grasshopper pierced with a pin or held with small forceps so that the examination may be quickly and easily made. Examine first with the naked eye, and then with a hand lens or a dissecting microscope.

I. - Take a general but careful view of the external features of the grasshopper. Lift the wings; note their number and place of attachment. Observe the number of pairs of legs and the location of the anterior and posterior pairs.

II. - There are three principal divisions of the body, head, thorax, and abdomen. Move the head gently from side to side to see the line of division between it and the rest of the body. Examine the long tapering posterior part of the body: this is the abdomen. Between it and the head lies the third great division of the body, - the thorax. The anterior margin of the thorax passes directly in front of the first pair of legs, and the posterior boundary is just back of the third pair of legs. Study the thorax carefully, remembering that the two pairs of wings and the three pairs of legs are all attached to it.

III. - You have already noticed that the abdomen is divided into segments, or somites, in a way somewhat similar to the abdomen of the lobster, but with less freedom of motion. Look for a similar but less marked series of divisions in the thorax. There are really three segments in the thorax, each bearing a pair of legs. See the first of these, - the prothorax, - easily distinguished by the separation from the head in front and from the rest of the thorax behind. The 
second and third divisions are not so well defined, and do not move upon each other. The division may be made out, however, by observing certain lines which represent the union of the two. On the ventral surface this line will be found behind the second pair of legs ; trace it up along the sides and back. The middle segment thus distinguished is the mesothorax, and the hind segment is the metathorax.

IV. - Notice that the position of the head is at right angles to the body axis. Compare it in this respect with the lobster. Study the long slender projections - the antennæ, or feelers - on the front of the head. See with a lens their jointed structure. Notice the peculiar surface of the large compound eyes. Between the compound eyes, find three small ocelli, or simple eyes.

V. - Begin the study of the mouth parts by finding on the lower side of the face a movable flap - the labrum, or upper lip. Observe this carefully, then remove it and see directly beneath it the mandibles, or jaws, - one on each side; these are hard, black, toothed structures. Press them apart, and then pull them out carefully with pointed forceps. You thus bring into view a dark brown, spindle-shaped organ in the centre of the mouth: this is the ligula, or tongue. The entrance to the gullet is a small round opening above the base of the tongue. Below where the mandibles were, the maxillæ are now to be seen, one on each side. Pull one of these out, being careful to get the whole of it, and by the aid of a lens identify the following parts :-

$a$. The basal segment.

$b$. The jointed appendage on the outside, called the maxillary palpus. 


\section{Branch Arthropoda}

c. The large thin plate-like blade.

d. The more slender inner portion, which is the true maxilla.

e. Directly below the maxillæ lies the labium, or lower lip. On each side a palpus is attached: these are the labial palpi.

Make good-sized drawings of each of the mouth parts, labelling each.

VI. - Observe carefully the general nature of the legs and their attachment to the body. Remove one of the front legs and identify the following parts: the coxa, the short segment next the body; the trochanter, a short segment connecting the coxa with the femur, the first long segment; beyond the femur is another long segment, the tibia, which articulates with the tarsus, or foot, a series of short segments, the last of which is tipped with claws and has peculiar pads on its under surface. VII. - Remove one of the hind legs and make a careful drawing showing each of its parts. Why should the femur and tibia be so much longer in these legs than in the front and middle pair?

VIII. - Carefully turn back the outer pair of wings. Note that they are the anterior pair. To which division of the thorax are they attached? Lift one of the under wings and notice its attachment to the thorax. Spread it out and observe its fan-shaped appearance. See that it is composed of a membrane stretched over a framework of veins.

IX. - On each side of the mesothorax, over the second pair of legs, find the spiracle, a slit-like opening to the airtubes. Find another spiracle on the prothorax.

$\mathrm{X}$. - Bend the abdomen and notice the play of the segments upon each other. Theoretically each segment 
is divided into four parts: the tergite is the dorsal portion, a pleurite is on each side, and the sternite forms the ventral surface. See if you can distinguish these parts. Remember the structure of the segments in the lobster.

XI. - Study the first segment; that is, the one next to the thorax. Its sternite is not easily seen, but on each side above you will find a nearly circular cavity covered by a thin membrane. This structure is believed to serve as an ear. On the side of the abdominal segments find spiracles similar to those on the thorax. Are spiracles found on all of the segments? Is there more than one pair on any somite?

XII. - Notice that the somites at the posterior end of the abdomen are greatly modified. In the case of female specimens the abdomen ends in two pairs of pointed processes curving outward. When these are brought together they form a device for burrowing into the ground, and they serve as the ovipositor of the insect. In the male the end of the abdomen is much blunter. XIV. - Draw a side view of the grasshopper.

\section{THE DRAGON-FLY}

Dragon-flies are abundant about ponds in summer. Large specimens serve admirably for showing the general structure of an insect.

I. - Find the three great divisions - head, thorax, and abdomen - into which the body axis is separated.

II. - Compare the relative sizes of each of these divisions with the relative sizes of the same parts in the grasshopper.

III. - Between which parts does the division line show most plainly? 


\section{Branch Arthropoda}

IV. - Notice that the head, convex in front and concave behind, is given its peculiar shape by the very large compound eyes.

V. - Using the lens, find the short antennæ. How many segments has each?

VI. - Near the base of the antennæ find two small simple eyes, the ocelli.

VII. - Find a third ocellus between and above these two ocelli.

VIII. - Notice a slight projection covered with hairs, sheltering the ocelli.

IX. - In examining the mouth parts, first observe the large size of both upper and lower lips.

X. - Push these parts aside so that the mandibles - the large toothed jaws - may be seen. Find beneath the mandibles another pair of jaws, the maxillæ; these consist of several parts, as in the grasshopper, and should be carefully removed and studied under the microscope.

XI. - Examine the thorax carefully, to find its three segments, - the prothorax, the mesothorax, and the metathorax. The lines of division may most easily be seen on the ventral surface. Remember that each of these divisions bears one pair of legs.

XII. - Note the relative size of the thoracic segments. The enlargement of which one gives the insect its peculiar hunchbacked appearance?

XIII. - Demonstrate the truth of the statement that the anterior and posterior pairs of wings are attached to the mesothorax and metathorax respectively. Reflect upon the attachment of the wings in the other insects studied, and remember that the place of attachment is constant. 
XIV. - Note the structure and size of the dragon-fly's wings as compared with those of other insects. Notice the relative size of the front and hind wings. What bearing do these characters have upon the habits of life of the dragon-fly?

XV. - Study the veins of the wings. Near the middle of the front margin find a slight notch connected with a short transverse vein. This structure is called the nodus. Its presence is an important characteristic of this group of insects.

XVI. - Notice the legs. Are they large or small? Does the dragon-fly walk much?

XVII. - Beginning with the segment next the body find the following parts of one of the legs : coxa, trochanter, femur, tibia, and tarsus.

XVIII. - Study the claws on the tarsus. To what special use are they likely to be put?

XIX. - Find the ten segments which compose the abdomen. The division between the segments is indicated by ridges which completely surround the joints. Bear this in mind when determining the segments nearest the thorax.

XX. - In any single segment point out the parts, called the tergite, pleurite, and sternite. (Refer if necessary to page 68.)

XXI. - Find the spiracles, or breathing pores, on the pleurites. What is their position?

XXII. - Study the terminal segment. In the female this segment is large and rounded; in the male it has four pointed appendages.

XXIII. - Make a drawing of a dragon-fly as seen from above. 


\section{THE BUTTERFLY}

Before mutilating the specimen, study carefully its general structure. Notice the relative sizes of the wings and body, the markings on the wings, and the hairy covering of the body.

I. - Note the relatively large size of the compound eyes; examine the outer surface of one with a lens to see its honeycomb appearance.

II.- Are there any ocelli ? If so, where are they situated? III. - Examine the antennæ. What is the general shape? About how many segments are there in each? Which segments are the longest? How does the basal segment differ from the others?

IV. - Notice the long coiled sucking organ - the proboscis - at the mouth. Is it composed of one or two pieces? Notice the two jointed hairy organs beside the proboscis : these are the labial palpi. The proboscis is formed of the modified maxillæ.

V. - Notice the small thorax in close connection with the head. Compare the connection with that found in the dragon-fly.

VI. - Observe the large mesothorax bearing the front pair of wings. Find the suture between it and the metathorax which bears the posterior wings.

VII. - Notice the fragility of the legs. Give a reason for their small size as compared with those of the grasshopper.

VIII. - Are the front legs as large as the others? When you have a chance to see a large butterfly walking, see how many feet it uses.

IX. - Place a piece of the wing under the low power of the microscope. Observe the shingle-like arrangement 
of the scales. What difference is to be seen at the edge of the wing?

X. - Scrape off a few of the scales on a glass slide and study with the high power of the microscope. Notice the structure and the difference in shape. Draw five specimens, each different from the others.

XI. - Scrape off a few of the hair-like scales from the thorax and study them in the same way. Can you find any scales intermediate between the short, broad ones and the long, hair-like ones?

XII. - Count the abdominal segments. If necessary, remove some of the hairy covering to show the joints. XIII. - Rub off the scales from the sides of the body and find the spiracles. How many are there?

XIV. - Is each segment made of four parts - tergite, two pleurites, and sternite - as in other insects?

XV. - Make a drawing of the butterfly as seen from above when its wings are expanded.

\section{THE SPIDER}

I. - Segmentation of the Spider. Notice how the body axis is divided into two great divisions by a deep constriction near its middle. The anterior division is made up of the head and thorax, and is called the cephalothorax. The posterior division is the abdomen. How does this division of the body axis compare with that of the lobster? Notice the entire absence of any segmentation either in the thorax or abdomen.

II. - Appendages of the Head. The parts of the head must be studied with the low magnifying power. Are there any antennæ? Scattered over the anterior part of the head find the small black ocelli, - generally four 


\section{Branch Arthropoda}

pairs. Directly below the eyes is the pair of broad, thick mandibles, or jaws. Find a sharp-pointed claw on the tip of each mandible. It is within these claws that the poison glands are situated. Directly below the mandibles is another pair of jaws, or maxillæ. The maxillæ themselves are short and thick, but each possesses a long jointed appendage, or palpus, which looks very much like a foot. See the mouth between the pair of mandibles and the pair of maxillæ.

III. - Appendages of the Thorax. The thorax bears four pairs of legs, a number characteristic of spiders. The maxillary palpi just mentioned, though smaller than the legs, are sometimes taken for a fifth pair of legs. See that this point is clearly understood. Determine the number of segments in the legs. Beginning with the one next the body, they are coxa, trochanter, femur, patella, tibia, metatarsus, and tarsus. The trochanter and patella are generally very small.

IV. - Appendages of the Abdomen. Near the posterior end of the abdomen, notice a blunt bunch of finger-like projections, the spinnerets, usually six in number. To see them well it will be necessary to use a low magnifying power. The spinnerets are the organs that form the spider's silken thread. In the end of each spinneret there are a great number of small tubes. A peculiar fluid is forced out through these tubes which hardens as soon as it strikes the air, thus forming the silk thread.

Try to find a hard rough structure surrounding a pore or spiracle just in front of the spinnerets. This opening leads to a breathing apparatus. Two small openings to another breathing system may be found on the ventral side of the abdomen, near its union with the thorax. 


\section{THE CLASSIFICATION OF THE ARTHROPODA}

The branch Arthropoda which includes the jointed-footed animals, is one of the largest and most important zoological divisions. Its members differ from the Annulata in having jointed legs or other appendages attached to the body segments, and from the Mollusca in having the body definitely divided into segments. They have an exoskeleton composed of chitin or of chitin and calcium combined. They possess a specialized nervous system, composed of a dorsal brain and a double row of ganglia along the ventral side of the body cavity. In general, the body is bilaterally symmetrical.

The following classes of Arthropoda are now recognized by leading authorities :-

Class I. Crustacea. Lobsters, Crabs, Shrimps, and Barnacles.

Class II. Onychophora. Peripatus.

Class III. Myriapoda. Centipedes and "Thousand-legs."

Class IV. Insecta or Hexapoda. Bees, Beetles, Butterflies, and other insects.

Class V. Arachnida. Spiders, Scorpions, and Mites.

The first class, the Crustacea, includes the smallest as well as the largest forms of the Arthropoda; forms which vary in size from the microscopic Cyclops to the huge crabs, some of which are of enormous size. The typical crustacean is made up of twenty-one segments, divided between the three great divisions of the body, - head, thorax, and abdomen. The segments of the head and thorax have become united, forming the cephalothorax, while the individual segments of the great divisions of the body have become so fused together that it is difficult to distinguish the typical number. There are two pairs 
of antennæ, the smaller of which are called antennules. The body is covered with a chitinous integument, a large part of which is usually hardened with lime. This covering is cast off at frequent intervals during the growth of the animal. During development many crustaceans pass through a series of peculiar changes of form which are called metamorphoses. Nearly all are water breathers; some live in fresh water or in moist situations on the land, but the great majority are marine.

The second class, Onychophora, includes only the single remarkable genus Peripatus. The members of this genus are peculiar creatures, which appear to be a connecting link between the Annulata and the Arthropoda. Only a few species are known, all inhabiting tropical regions. The members of the third class, Myriapoda, have a distinct head, but the segments of the thorax and abdomen form a continuous series. The number of these segments is indefinite. Each bears one or sometimes two pairs of legs. They breathe air by means of tracheæ. The centi. pedes and millipedes or "thousand-legs" are typical representatives of this class.

The fourth class, Hexapoda, differs from the preceding classes in having three distinct divisions of the body, head, thorax, and abdomen. The head is composed of several united segments; the thorax of three segments; and the abdomen of from seven to eleven segments. There are six legs, one pair being borne by each thoracic segment. The thoracic segments also bear on their dorsal surface one or two pairs of wings. The nervous system has a wonderfully complex specialization, furnishing the insect with great instinctive powers. Growth takes place only during the early or larval life, and in many forms complicated transformations occur. 
The class Arachnida includes the spiders, scorpions, and mites. In these there are two chief divisions of the body, - the cephalothorax and abdomen, eight legs, no antennæ, and generally no distinct transformations. With unimportant exceptions they breathe air either by means of tracheæ or of book-lungs, and have a varying number of simple eyes upon the cephalothorax. 


\section{CHAPTER VIII}

BRANCH MOLLUSCA: THE OYSTER, CLAMS, AND THEIR ALLIES

\section{THE FRESH-WATER CLAM}

\section{EXTERNAL ANATOMY}

I. - Place a clam in a glass of tepid water and observe the gradual opening of the shell, and the protrusion from one end of a white, blunt, muscular projection, the so-called foot. This marks the anterior end of the animal, and by its protrusion and retraction the clam steadily moves along the sand, leaving grooves made by the sharp edges of the shell. In removing the creature from the water in preparation for the study of its structure, notice how the two halves of the shell are quickly brought together and the foot withdrawn.

II. - The lateral surfaces are easily distinguished. They are the broad oval surfaces upon which the clam rests when placed upon the table. The sharp edges of the two parts of the shell form the ventral surface. It is this surface that makes the groove markings in the sand, mentioned above. The opposite thicker edge is the dorsal surface.

III. - With a clear idea of the lateral, dorsal, and ventral surfaces in mind, determine the anterior and posterior ends by the aid of the following directions. On the 
dorsal surface find two prominences, the umbones, near together. Notice that the umbones are nearer one end than the other. The end to which they are nearer is the anterior end, and the opposite extremity is the posterior end.

IV. - We have noticed that the entire shell is divided equally into two parts, or valves. It is for this reason that the term Bivalve was given to the class to which the clam belongs. Find a strong, hard hinge or ligament near the umbones that joins the valves.

V. - With some sharp instrument carefully force the ventral edges of the shell apart, putting some object in the space to hold them in position. Then pushing aside the ruffled edge of a membrane, insert the knife edge close under the valve and carefully push away the soft membrane clinging to its inner surface.

VI. - By forcing open the valves a little farther, you will be able to see near each end a hard, smooth, white pillar of muscle fastened to the inner side of the valve. These pass directly through the body, and are attached in similar positions to the opposite valve. Carefully cut out these muscles close to the valve. The springing open of the latter shows why the muscles are called the adductors. Without disturbing any of the parts, force the two valves together, and notice the spring exerted by the ligament, or hinge. Remember to study the mechanism causing this action after the soft parts have been removed, or on other shells.

VII. - Study the concentric rings radiating from the umbones. These are the growth lines of the shell as it was gradually secreted by the soft membrane first seen when the valves were opened. 


\section{Branch Mollusca}

\section{INTERNAL ANATOMY}

VIII. - The shell is a true exoskeleton, and its removal does not expose the interior or body cavity of the clam. On account of the size of the animal and its lateral compression, we can do no more than indicate the relations of the body cavity and alimentary canal.

IX. - The membrane above mentioned as found closely adhering to the inner side of the shell is the mantle. This has two lobes, corresponding in shape to the valves of the shell. Demonstrate this fact. Lift the uppermost lobe carefully to determine its place of attachment. It is simply an outgrowth of the body wall. At the posterior end find two well-defined oval openings, formed by the two mantle lobes coming together. These two openings together form the siphon. In the salt-water clam the two lobes of the mantle have developed into a siphon that extends outward, sometimes an inch or more beyond the shell: a black, hard, elongated projection, through which these openings pass as wholly closed tubes. Water containing food material passes in at the ventral or lower opening, and out from the dorsal opening. It may be necessary to remind the student that we are still talking about the posterior end of the animal, and that we have not yet penetrated its body wall.

$\mathrm{X}$. - By raising the mantle lobe examine the exposed, hard, white, muscular foot. This is also an extension of the body wall, and within its base (the visceral mass) are embedded the long coils of the stomach region of the alimentary canal.

XI. - On either side of and posterior to the abdomen find the gills, a pair of ribbed membranous organs. Just 
anterior to the foot, and below the anterior adductor muscle, search for the mouth, a small opening, sometimes difficult to find. Force a bristle into this up to the stomach coils.

- XII. - Attached to the walls of the body, and on each side of the mouth find a pair of soft triangular flaps, the labial palpi.

XIII. - Gently detach the body of the clam from the shell close under the hinge. Where the two mantle lobes unite to form the dorsal body wall, the latter is so thin that you may look through it into the body cavity and see the straight intestine passing from end to end. Try to see the pulsing, colorless, ventricle of the heart, through which the intestine passes, though the cavities of the two have no connection. With pincers and sharp-pointed scissors carefully lift and cut the body wall so that the boundaries of the body cavity and its organs may be more easily seen.

XIV. - Trace the intestine forward toward the mouth. Examine the dark brown mass surrounding the coils of the stomach. This is the liver (very evident in stews of the edible clam). As is the usual function of that organ, it secretes a digestive fluid that passes into the interior of the alimentary canal.

XV. - Trace the intestine backward, and notice that it ends in a space into which the dorsal opening of the siphon opens. This space is called the cloacal chamber. XVI. - Determine the course taken by the water that passes in at the ventral opening. Notice that it bathes the gills, the lower part of the body wall and foot, and the inner side of the mantle lobes; then it passes forward to the labial palpi and the mouth. The cilia which cover the labial palpi keep up a constant vibratory 
motion, causing currents in the water to pass into the mouth, so that the food in such currents may be taken by the clam. The gill chamber is the large cavity in which the gills are suspended: it is bounded mainly by the mantle. The lower end of the siphon opens into it.

XVII. - It was stated above that currents of water entering the lower opening of the siphon escape through the dorsal. To make this evident and to demonstrate the relation between the cloacal and the gill chambers hunt for small openings in the floor of the former. Water passes through these from the gills into the cloacal chamber and thence out.

XVIII. - The Nervous System may be very difficult to make out in a fresh specimen. Better results are likely to be obtained by hardening the specimen in alcohol. Remove the mussel entirely from the shell, and with the needles search in the median ventral line between the gills and directly under the posterior adductor muscles for a pair of yellowish masses, or ganglia. Still another pair of these nerve centres may generally be seen, lying near the surface, one on each side of the mouth, close to the bases of the labial palpi. The pedal ganglion may be found in front of the intestine in the foot. These nerve centres are connected by nerve threads called connectives. Trace out as much of the connecting system as possible.

XIX. - The Reproductive Organs will not be easy to study. They lie in the abdomen, below and behind the liver. They open by ducts into the gill chamber.

XX. - Make two drawings of the clam: a side view of the shell, and a diagrammatic view of the internal structure. 


\section{THE FRESH-WATER SNAIL}

Fresh-water snails may be easily found at almost any season of the year. In summer they are abundant on the vegetation in ponds and slow-running streams, while in winter they may be easily procured by scraping the bottom of the pond with a collecting net. This is especially feasible in springs that do not freeze over. This outline is for one of the species with conical, pointed shells. Have one or more specimens in the hand, and one or more live ones in a beaker aquarium.

I. - Study the specimen as a whole. Notice the three distinctive characters of the molluscs, - the foot, the mantle, and the shell secreted by the mantle. Make a drawing of a side view of one with its body and tentacles extended.

II. - Study the shell. Can the animal part with it? Notice the pointed end: this is the apex. Notice the open end: this is the aperture. Notice the spiral groove: this is the suture. Notice the divisions of the shell made by the suture: these are the whorls; the large anterior one is the body whorl, while the others together form the spire. The axis from the centre of the aperture to the apex is the columella. Notice lines around the shell parallel to the lip: these are the lines of growth.

III. - Hold the shell with the apex toward you: if the suture turns to the right, the spire is a right-hand or dextral spire; if it turns to the left, it is a left-hand or sinistral spire. Or hold the shell with the aperture toward you: if the aperture is to the right, the shell is dextral; if to the left, it is sinistral. Which is your specimen? 
IV. - Study the locomotion of the living snail : how is it effected? Can the snail move in any direction in the water or on a damp surface outside? How does the large foot on which it moves differ from that of the clam? Can you detect any motion of the different parts of the foot while the snail is moving?

V. - Where are the tentacles? How many are there? Can you see a small spot at the base or the tip of the tentacles? These spots are the eyes.

VI. - As the snail crawls up the wall of the aquarium or along the surface film of the water, you can see the mouth. Is it longitudinal or transverse as compared with the direction of the body? Describe its movement in opening and closing. When it is open, can you see a black object moving back and forth? This is the tongue. When magnified this tongue is seen to be jagged in outline.

VII. - Do snails in the water come to the surface occasionally? If they do, can you see a bubble of air escaping from an opening in the mantle of each under the lip of the shell? This is the opening to the curious lung these snails have.

VIII. - The eggs of snails may be frequently found on the sides of the aquarium. They appear as small granules imbedded in a gelatinous mass. Examine some of them through a lens.

IX. - Make a drawing of a side view of the snail and its shell.

\section{THE SQUID}

The squid is a marine mollusc which is frequently caught by fishermen in their nets.

I. - Study the animal as a whole. What characters should you say ally it to the class Mollusca? Notice the long 
cylindrical body, covered by a mantle and tapering to a point. See the distinct, slightly movable head. Find the large eyes, the arms or tentacles, and the mouth between the bases of the arms. Find a fold in the membrane directly back of each of the eyes: these are the olfactory lobes. See the opening in the siphon tube back of the head on the lower side of the body, and the wide terminal fins toward the posterior end of the body.

II. - Study the tentacles. How many are there? How do they vary in size? Notice the two rows of suckers on the inner margin of the tentacles: how are they arranged? Of what especial use are the suckers? The pair of long arms are called the grasping arms: what is their shape? What is the arrangement of the suckers upon them?

III. - Study the mouth. What is its shape? Notice the peristome. Open the mouth and notice the large chitinous jaws. Which is the larger? The mouth is surrounded by projections of the skin: how many and of what use are they?

IV. - Study the large eyes. Is their position an advantageous one?

V. - Study the siphon tube, beneath the head and projecting from between the mantle and the neck. Study the structure of the orifice.

VI. - The body is enclosed in a mantle. From what do the large terminal fins on the posterior third of the body arise? These fins are used for swimming. Around the neck you will find a cavity. This is the external part of the mantle cavity. A small projection of the mantle over the middle of the head is the pen. The squid can take water into the mantle cavity 
and forcibly expel it through the siphon tube, and this enables it to dart through the water with great rapidity.

VII. - Make a drawing of the ventral view of the squid.

\section{THE CLASSIFICATION OF THE MOLLUSCA}

The Mollusca is the great branch, or phylum, to which belong the mussels, snails, limpets, and cuttlefishes. Many of its members are believed to be closely allied to worms, though the members of the two branches differ widely in external appearance. In the development of the Mollusca the segments have been fused together, while the skin has secreted a calcareous shell; the relative length of the body has decreased, and in the lower groups there is no distinct head. The alimentary system is greatly developed, especially the liver. The phylum includes terrestrial, freshwater, and marine forms. There are three principal classes :-

I. - Pelecypoda. Oysters and Clams.

This class includes "laterally compressed Mollusca without separated head, with bilobed mantle and bivalve shell, composed of a right and left half and connected by a dorsally placed ligament." The sexes are generally separate, and there are large gill-plates on account of which the class has commonly been called Lamellibranchiata. The locomotive organ consists of a single median muscular foot, and the parts of the body are arranged with bilateral symmetry. Both salt and fresh water forms are included, all of which breathe by means of gills.

II. - Gastropoda. Snails, Slugs, and Limpets.

The members of this class usually have a shell in a single piece which commonly has the shape of a spiral 
cone. The body is not symmetrical, and in front of the foot there is a head which bears the tentacles and eyes. These animals are widely distributed: the largest number live in salt water, but many live in fresh water, and many are terrestrial. Some breathe by means of gills; others by means of lungs.

III. - Cephalopoda. Cuttlefishes and Squids.

This class includes the highest molluscs, the most important examples being the Cuttlefish, Squid, Octopus, and Nautilus. The members of it are bilaterally symmetrical with the head separated from the body by a slight constriction. There are two well-developed eyes, a rasping tongue, a beak, and eight or more tentacles. The ganglia of the head are somewhat protected by a covering. 


\section{CHAPTER IX *}

\section{BRANCH CHORDATA : THE VERTEBRATES}

\section{THE PERCH}

\section{EXTERNAL ANATOMY}

I. - General Form. Study the graceful outline of the fish from a side view. From a dorsal view, see how the body is compressed laterally. Observe how the head, although flattened at the tip, passes with graceful curves into the body. Account for the compressed body, flattened head, and the absence of a neck by reference to the animal's habitat and locomotion. Notice the absence of any segmented division of the body axis. Segmented structures will be found to exist, however, when we study the skeleton and muscles. Study the coloration of the fish. Account for its dark dorsal and light ventral surface by reference to its needs of selfprotection. Notice the alternating perpendicular bands of black and white along the sides. Explain how this arrangement of color also makes the fish less conspicuous in its natural haunts.

II. - Exoskeleton. Study the scales of the perch. Remove some of them, and with the low power of the microscope see the thin covering. Draw one. The scales themselves are the outgrowths of the inner or true skin, while their covering corresponds to the outer skin or epidermis of the higher animals. 
III. - Appendages. Study the two fins running along the dorsal median line. They are made up of a web supported by hard spines. How do the spines in the two fins differ? The tail is called the caudal fin. What kind of rays has it? When the caudal fin is symmetrical, it is said to be homocercal; when it is bent so that it is unsymmetrical, it is said to be heterocercal. Which is the case in the perch? On the mid-ventral side of the body, just in front of the caudal fin, find the anal fin. Note the fact that all fins studied above are median or single, i.e. never in pairs. Next observe a pair of fins (pectoral) just back of the head, one on each side of the body. They correspond to and indeed are homologous with the fore legs or arms of the higher animals. Back of the pectoral fins, and nearly on the ventral line, find the pair of pelvic fins, corresponding to the hind legs of the higher animals. Take a general view of the fins with reference to their uses. Tell which keep the animal in an upright position, and which give it propelling power and guidance.

IV. - Other Organs. Study the action of the jaws, noticing that both have movement. Is the action up and down or from side to side? Place a finger in the mouth to feel the teeth, noticing their slanting direction. Study the size and position of the eyes. Find with the forceps the bony socket encasing the eyes. Move the eye itself to find its field of vision. Are there any eyelids? Find the nasal opening in the upper lip. Find the anal opening just in front of the anal fin.

V. - Breathing Apparatus. Find a large, slit-like opening on each side of the head just back of the mouth which communicates directly with the mouth cavity. These are the gill-chambers, and the flaps closing over them 
are the gill-covers. The gill-arches are the four bony arches standing side by side within the gill-chambers. Attached to the gill-arches are the red filamentous structures, the gills. Are the gill-chambers in direct communication with the exterior from both sides; if so, are the gills constantly bathed in water? As the blood passes through the many filaments of the gills, opportunity is given for it to exchange its carbonic acid for the oxygen of the water.

\section{INTERNAL ANATOMY}

VI. - Body Cavities. Insert the point of the scissors just in front of the anal opening, and cut through the body wall to the gill-slits. Push the flaps aside, and observe the main body cavity. Notice how the cavity with its organs is crowded forward, leaving the posterior parts for the strong muscles. Notice the shining membranous lining, the peritoneum. Near the anterior end of the body cavity you may find a membranous partial partition corresponding to the diaphragm of the higher vertebrates.

VII. - Blood System. Near the middle of the smaller anterior cavity a dark reddish body, the heart, will be found. There are but two cavities in the heart, - the rather angular, thick-walled ventricle and the dark, irregular auricle. You may be able to find connected with the auricle a dark, thin-walled vessel, the venous sinus, extending across the body cavity. The venous sinus receives the blood from the veins, and passes it on to the auricle. Find and trace as many vessels as you can connected with the heart or venous sinus.

VIII. - Digestive System. Pass a blunt instrument down 
the œsophagus to observe its union with the stomach. Then follow the intestine from the stomach in its not long course to the anal opening. The large, reddish lobed object lying in the anterior part of the body cavity is the liver. Try to make out its connection with the intestine. The gall-bladder is a small, greenish body, partly concealed by and closely connected with the liver.

IX. - Reproductive and Excretory Organs. In the vertebrates, as in many invertebrates, the sexes are separate. So in the fish we must look for testes or ovaries, never both. The appearance of the female organs or ovaries varies greatly with the season. In spawning time the ovaries may be so distended that they cover all the other organs. At other times they have the appearance of a single white body lying near the intestine. A delicate tube leads from this to an opening toward the posterior end of the body. If the specimen is a male, the testes will be found to be a pair of white bodies lying in the posterior dorsal part of the abdominal cavity. Ducts may be found passing to an opening toward the posterior end of the body. After clearing away the intestine and reproductive organs, a broad, flat, membranous sac may be seen, if it has not already been punctured: this is the air-bladder; it is connected with the œesophagus. Its function is to decrease the specific gravity of the fish by filling it with air. Remove the air-bladder, and find two long, dark, slender bodies, the kidneys. Trace their ducts to the outlet near the anal opening. Near the outlet a pinkish sac, the urinary bladder, will be found. X. - Endoskeleton and Central Nervous System. Cut the flesh away from the dorsal surface of the fish, exposing the backbone as completely as possible. Notice 
that this flesh is composed of muscle segments or myotomes. Observe the jointed or segmented nature of the backbone or spinal column. Its lateral bony processes are analogous to the ribs of the higher vertebrates. Each separate segment is a vertebra. Passing along a closed tube within the spinal column is the spinal cord, ending anteriorly in the brain. The two (spinal cord and brain) constitute the central nervous system. Nerves pass from this through openings between the vertebræ to various parts of the body. Break the connection between two of the vertebræ to see the cavity filled by the spinal cord. Open the cranium, or brain case, by removing carefully the dorsal surface of the head just back of the eyes. Study the lobes of the brain now exposed. Follow the continuation of the brain into the spinal cord. Without injuring the lobes of the brain, carefully dissect away sufficient surrounding tissue to see the large optic nerves passing to the eyes. If the lobes of the brain still remain complete and uninjured, follow out the different parts. The small median lobe extending backward is the cerebellum. The pair of large rounded lobes directly in front of the cerebellum, constituting the broadest part of the brain, are the optic lobes. The cerebral lobes, or hemispheres, are much smaller, and lie directly in front of the optic lobes nearly on the median line. The somewhat flattened posterior part of the brain, passing from the cerebellum into the spinal cord, is the medulla oblongata. Make a drawing of the brain. 


\section{THE FROG}

\section{EXTERNAL ANATOMY}

I. - General. Feel of the frog's skin, noting its smooth, slimy nature. The moisture is a secretion from the glands in the skin. Note the general temperature of the body. It is cold even in life. Study the color markings of the dorsal and ventral surfaces, and give reasons for such coloring. The frog has the power to change its color, bringing it into closer harmony with its surroundings. The frog is placed in the group of animals called Amphibia. All Amphibians belong to the larger group called Vertebrata. Fishes, reptiles, birds, and mammals, besides Amphibians, are vertebrates. Fishes and reptiles, like Amphibians, are cold blooded. Notice that the frog has no outer skeleton. Note the absence of an external division of the body axis.

A segmented condition will be found to exist, however, when we study the skeleton. Examine the limbs with special reference to the animal's habit of locomotion. Is the animal well adapted to its environment in this respect? Remember that the number of limbs possessed by the frog is the maximum for vertebrates.

II. - External Openings. Examine the nature and position of the mouth and cloacal opening. Study the position of the eyes with reference to their field of vision and protection. In the anterior parts of the upper jaw find two small openings into the nasal cavities. Push the forceps or some blunt instruments through them into the mouth. Behind each eye find a circular disk of tightly stretched membrane, the external apparatus of the ear. 
Inside the mouth at the back find the eustachian tube, a passage leading to the drum of the ear.

\section{INTERNAL ANATOMY}

III. - Dissection. With scissors or sharp scalpel cut the skin from the edge of the lower jaw along the median ventral line to the cloacal opening. Notice how loosely the skin is attached to the body. Where is the principal place of attachment? Make lateral slits in the skin and pull away the flaps, pinning them if necessary. Remove the skin from the legs in the same manner. Observe the development of the powerful chest muscles ; also the muscles in the hind legs used as the propelling power in long leaps. Next, cut the body wall from end to end, in a similar manner to the incision of the skin, being very careful not to disturb any of the viscera beneath. Make lateral slits and pin back the flaps of the body wall, exposing the internal organs. A circlet of bones to which the legs are attached passes over the chest just above the heart. Cut these with strong scissors.

IV. - General. Recalling the general plan on which the earthworm and lobster are built, you will remember that it is a tube within a tube. The wall of the outer tube, being the body wall, encloses the body cavity; while the inner tube is the alimentary canal, with its two openings. Find a similar structure now revealed in the case of the frog. The large cavity holding the various organs, or viscera, is the body cavity, or outer tube, and through this passes the alimentary canal, or inner tube. The latter is now partly visible as the light-colored stomach or intestine. 
V. - Biood System. Just beneath the position of the chest bones the heart may be seen. It is a cone-shaped body, darker at the apex. There are only three chambers, - one ventricle and two auricles. The ventricle forms the apex of the cone and has walls much thicker than those of the auricles. Give reasons for this. Notice that there is no blood fluid in the body cavity. The blood circulates in a closed system, passing from the heart in arteries and returning in veins, instead of being left to find its way back to the heart by contractions of the body. Observe the large vessels leaving the heart; the arteries cannot be easily distinguished from the veins. Follow the vessels as far as you can without disturbing the other organs.

VI. - Digestive System. Without removing the viscera, study the entire alimentary tube and its appendages, with the aid of the following directions: Move the jaws up and down. Do they move in the same direction as the jaws of insects or crustaceans move? Notice the attachment of the tongue at its anterior end. The posterior end is moistened by a sticky secretion from the roof of the mouth, and protruded for the prehension of food. The mouth opens into the œsophagus, and thence into the stomach - the elongated, thick-

- walled enlargement of the tube. Pass some blunt instrument down the œsophagus, or inflate with a tube to observe the relation of the mouth, œsophagus, and stomach. From the stomach follow out the small intestine, large intestine, and cloaca, the last enlargement. Into the cloaca pass the contents of the reproductive organs.

VII. - Appendages of the Tube. Find the liver, a darklobed, very conspicuous body, lying near the heart. 
Partly concealed by the lobes of the liver, find a small, spherical, dark green body, the gall-bladder. Is it connected with the liver and intestine? Find somewhat closely connected with this a long, irregular, pinkcolored body, the pancreas. Trace out the ducts of the pancreas, gall-bladder, and liver as well as possible. The red spleen is farther back in the abdominal cavity. VIII. - Respiratory System. Find the dark, thin-walled, inflated bodies, the lungs, one on each side of the heart. Through their walls runs a network of bloodvessels, thus bringing the blood into close connection with the air filling the lungs. In the floor of the mouth, just back of the tongue, find the slit-like opening of the larynx, a chamber which connects with the lungs. Pass something down the larynx to see the relation to the lungs.

IX. - Reproductive System. The frog, like all vertebrates, and many invertebrates, is unisexual, i.e. an individual possesses but one kind of sexual organs. If the specimen is a female, large, irregular bodies, the ovaries, will be found on each side of the posterior part of the abdomen. Within these are found the cells which develop into eggs. During the breeding season the eggs pass from the ovary into the body cavity, and from there to the exterior by oviducts. These are coiled, tubular organs, with a funnel-shaped opening, and they pass to the cloaca. The openings of the oviducts possess small cilia, whose vibrations guide the eggs into them, and as the eggs pass through they gather a mucus secreted by the walls of the duct. This mucus swells greatly on striking the water, and we may thus account for the appearance of the frog's eggs when seen in ponds. 
X. - If the specimen is a male, two small, oblong, lightcolored bodies, the testes, will be found, one on each side of the median line just anterior to the cloaca. They produce sperm cells that pass directly by minute tubes into the kidney and thence by the ureter to the cloaca and to the exterior, where they fertilize the eggs from the female.

XI. - Excretory Organs. Excretory organs are used to throw off the waste material of the body. Hence the lungs, kidneys, and skin may be grouped together as parts of the excretory system. We have here only to study the kidneys. These are two flat, oblong bodies, lying one on each side of the median line in front of the cloaca and dorsal to the testes. As the blood passes through the walls of these bodies, it is relieved of certain waste materials that pass through ducts, the ureters, into the cloaca by openings in its dorsal wall. The bladder is a colorless bag which opens into the ventral side of the cloaca. Find the ureters.

XII. - Skeleton. Cut away the viscera already studied, leaving the backbone, or spinal column, exposed on its ventral side. Cut away the muscles on the fore and hind legs without severing the ligaments that bind the bones. Notice that in its general plan the skeleton is made up of a central axis (spinal column) and its appendages (limbs, etc.). Notice the segmented character of the backbone. Each segment is a vertebra. The unsegmented posterior part of the axis represents the fused segments that form the tail in other vertebrates.

XIII. - Nervous System. This may be divided into two great divisions, - the cerebrospinal and the sympathetic. The cerebrospinal system is made up of the brain and 
the spinal cord, and is now wholly invisible within the cranium and the spinal column. The sympathetic system may be seen in the shape of white cords lying on the dorsal floor of the body wall on each side of the spinal column. It is connected with the cerebrospinal system by branches between the vertebræ. The function of the cerebrospinal system is to govern the action of the muscles attached to the skeleton (skeletal muscles), while the sympathetic system controls the action of the visceral organs. By bending, sever the connection between the vertebræ, in order to see the spinal cord lying in a cavity within the solid bone of the spinal column. Carefully remove the bone from the dorsal surface of the cranium to see how the spinal cord terminates in the brain.

The position of the central nervous system (cerebrospinal) lying in a tube parallel to and wholly separated from the main tube (body cavity), and on the dorsal side of the body is an important characteristic of vertebrates as distinguished from invertebrates.

XIV. - Study again the pectoral arch, - the circlet of bones supporting the forward legs. It corresponds to our collar bone and shoulder blade.

XV. - Study the pelvic arch - the bones supporting the hind legs. Study the bones of the fore and hind limbs, noticing the similarity between the two pairs in the arrangement of the bones. Make comparisons between the bones of the limbs of the frog and those of the higher vertebrates by aid of the following outline :-

In the fore legs, beginning with the segments next to the body, the names and homologies are: $(a)$ humerus, which corresponds to the upper arm in man; $(b)$ ulnoradius, which corresponds to the ulna and radius of our 
forearm united; $(c)$ the small bones following, generally six, correspond to the bones of the wrist and may be called the carpus; $(d)$ next to the carpus there are five bones, corresponding to the bones of the palm of the hand (one is much smaller than the others and corresponds to the thumb) and all together compose the metacarpus; $(c)$ the remaining bones making the four fingers are called the phalanges.

XVI. - In a similar manner follow out the bones in the hind legs : (a) the femur corresponds to the thigh bone; (b) the tibio-fibula corresponds to the shank; (c) the tarsus corresponds to the bones of the ankle; $(d)$ the metatarsus corresponds to the bones of the foot; and (e) the phalanges correspond to the bones of the toes.

\section{THE BIRD}

The English sparrow will serve very well for the following study of the structure of a bird.

\section{EXTERNAL ANATOMY}

I. - General. Study the general structure of the body, noting that it may be easily divided into head, neck, trunk, and tail. In the trunk find the thoracic and the abdominal regions. In what ways does the bird differ from the frog?

II. - Observe the hard beak composed of two mandibles. Which of these is movable? Find the tongue, extending it with a pair of forceps. Describe its surface above and below. Are there any projections upon it? Of what use might they be? Behind the hard part of the tongue find an opening - the glottis.

III. - Study the inner surfaces of the jaws. Find what 
appears to be a longitudinal opening in the roof of the back part of the mouth. Push a pin through the nostrils from the outside. Where does its point enter the mouth?

IV. - Study the eyes and eyelids. How are the latter attached? See if you can find the nictitating membrane which sometimes covers the eye of the living bird.

V. - Study the ear-opening. Describe its size and shape. VI. - Study the wings. How does their length compare with that of the body? How many joints in them?

VII. - Observe the kinds of feathers and their distribution over the body. Do you find on the trunk any feather tracts beside comparatively bare places? Take a long feather from wing or tail: see its central stem or axis, and the vane which is made up of a vast number of barbs which in turn branch into barbules. The barbules hold the barbs together. Are they more effective toward the basal or the apical end of the feather? Compare a feather from the ear and one from the breast with the long one. How do they differ?

VIII. - Study the legs: what bones should you think are covered by the feathers? Is there any system in the arrangement of the scales on the tarsus and toes? Notice the shape of the claws on the toes, and the protection along the under surface of the toes.

\section{INTERNAL ANATOMY}

- IX. - Lay the specimen on its back in the dissecting dish with its head pointing toward you. Cut the skin along the median ventral line, beginning at the posterior extremity of the lower mandible. Pushing back 
the cut skin, notice over the thorax the large and powerful pectoral muscles which control the movement of the wings. Which way do the muscle fibres extend?

X. - Circulatory System. Cut through the pectoral muscles and soft breastbone (sternum), extending the incision back through the abdominal walls, thus exposing the viscera of the thorax and abdomen. In the thorax see the heart. Lift it carefully and cut the connective tissues in such a way as to enable you to study the important blood-vessels. From the front of the heart on the left see the large aorta which comes from the left ventricle. Before turning backward this gives off the innominate arteries - one to the right and one to the left. Each innominate artery in turn has three branches; namely, a carotid, extending forward toward the head; a brachial, extending to the wings, and a pectoral, extending to the pectoral muscles. The large aorta extending backward may be studied a little later when the thoracic and abdominal viscera are removed. On its course it gives off various branches, - to the stomach, to the liver, and to the legs. Find three good-sized veins which pass into the right auricle, and the right and left pulmonary arteries which go from the right ventricle to the lungs.

XI. - Study the structure of the heart itself. By cutting transversely across the lower end see whether the ventricles are completely separated from each other. Now make a longitudinal section and study the structure of the valves that connect one chamber with another.

XII. - Mount a drop of blood upon a glass slide, and study the shape of the corpuscles as seen with a high power of the microscope. Make drawings of them. 
XIII. - Digestive System. Study the alimentary canal. Beginning at the mouth see the straight tube, the œsophagus, extending backward to the enlarged crop, and then continuing to the muscular walled gizzard. Open this: what is inside? What is the chief use of the gizzard? Back of the gizzard see that the alimentary tube continues as the duodenum, more or less curved and looped. Within this loop see the pancreas-a yellowish gland. Lift the pancreas and find where its ducts enter the duodenum. At this time study also the liver with its two large lobes, and find the greenish gall-bladder between them. Directly under the gizzard see the small, flattened, red spleen. The alimentary tube continues backward from the duodenum as the small intestine, much convoluted, until it enlarges in the cloaca near the posterior end. Notice the cœca on the small intestine. Make a sketch of the alimentary tube and its connections.

XIV. - Respiratory System. The cartilaginous trachea is easily seen extending from the mouth to the thoracic cavity, where it divides into the bronchi, one passing to each lung. Inflate the lungs through a tube inserted into the trachea through the glottis, where it opens into the mouth.

XV. - Reproductive System. If your specimen is a male, the oval glandular testes will be readily seen in the abdominal cavity after the alimentary system is removed. Find a convoluted vas deferens running from each to the cloaca. If your specimen is a female, you will see the glandular ovary. A single oviduct on the left side of the body opens into the cloaca. Only a vestige of the right oviduct remains.

XVI. - Renal System. When all the abdominal viscera 
are removed, the kidneys are to be seen as dark-colored, flattened bodies, fitting closely against the bones of the back, one on each side the spinal column. Find a tubular ureter running from each kidney to the cloaca. XVII.-Nervous System. If the head is cut off and placed in alcohol for a day or two, the brain will be hardened so it can more readily be studied. Remove the upper part of the skull by cutting with strong scissors from the beak over the eyes and around the back of the head, thus exposing the brain. Note these parts of it: the large cerebral hemispheres with the elongated cerebellum immediately behind on the dorsal side; the two olfactory lobes beneath the front part of the cerebral hemispheres, and the two optic lobes in front of and at the sides of the cerebellum. Make a drawing showing the parts of the brain as seen from above and another as seen from the side.

\section{THE CLASSIFICATION OF THE VERTEBRATES}

The highest branch in the animal kingdom is called the Chordata. "It comprises all the Vertebrate Animals (Fishes, Amphibians, Reptiles, Birds, and Mammals), together with the Urochorda, or Ascidians, and the Adelochorda, or Balanoglossus, and its allies. The name Chordata is derived from one of the most important of the few common features by which the members of this extensive phylum are united together - the possession either in the young condition or throughout life of a structure termed the chorda dorsalis, or notochord. This is a chord of cells, typically developed from the endoderm, extending along the mid-dorsal line above the enteric tube on the ventral side of the central nervous system. It becomes enclosed 
in a firm sheath, and forms an elastic supporting structure. In the Vertebrata (with the exception of Amphioxus and the Lampreys and Hagfishes) it becomes in the adult replaced more or less completely by a segmented bony or cartilaginous axis - the spinal or vertebral column." (Parker and Haswell.)

The branch or phylum Chordata is divided into three subbranches or subphyla, namely :-

Subphylum I. Adelochorda. Balanoglossus.

Subphylum II. Urochorda. Ascidians and Sea-squirts.

Subphylum III. Vertebrata. Fishes, Amphibians, Reptiles, Birds, and Mammals.

The first of these includes the remarkable worm-like animals belonging to the genus Balanoglossus. The second comprises the Ascidians or Sea-squirts, which are often called Tunicates and grouped together under the name Tunicata. The third includes the vertebrates proper, in which are found the highest animals.

In the subphylum Vertebrata, some of the very lowest fish-like forms have no skull, or development of the anterior end of the vertebral axis. These are classed under the head of Acrania. All the others, or those with a skull, are called Craniata. These are divided into six great classes, named below in the order of their natural development. The first four are cold blooded, and the other two are warm blooded.

Class I. Cyclostomata. Lampreys.

This class comprises comparatively few forms, which have in place of jaws a suctorial mouth; they have no fins or other lateral appendages, and only one nasal aperture. The Lampreys and Hagfishes belong to this class.

Class II. Pisces. Fishes. 
The members of this and the preceding classes are the lowest of the true vertebrates, not only in structure, but also in strength, intelligence, and sensibility. As a class, however, the fishes are superior to all the others in number and variety of forms. They live always in the water, are cold blooded, and breathe by gills. Their fins are homologous with the limbs of the higher vertebrates.

\section{Class III. Amphibia.}

The Amphibia are cold-blooded animals, having gills when young, and lungs when adult. In the early stages the tail is modified into a swimming organ. The eggs are deposited in the water or upon moist surfaces, the skin is soft and naked, and the skeleton is bony or ossified. There is no distinct neck. There are a number of orders of Amphibia, the lower including the newts and salamanders, or the tailed Amphibians, while the higher include the frogs and toads.

Class IV. Reptilia. Reptiles.

These are cold-blooded animals, distinguished from the Amphibia by never having gills, and from birds by the absence of feathers. With the exception of some of the turtles, they are carnivorous. The Reptilia includes the snakes, the lizards, the turtles, and the crocodiles.

\section{Class V. Aves. Birds.}

This is the most clearly defined class in the animal kingdom. Its members are air-breathing, egg-laying, feathered vertebrates with the front limbs developed for flying or swimming, and the hind limbs for perching, walking, or swimming. The bones are light and compact, and the neck is usually long. The birds are a group of great interest and of the greatest economic importance, whether we consider their direct value to man as food, or their indirect benefits in checking insect and other animal pests. 


\section{Branch Chordata}

Class VI. Mammalia. Mammals.

This is the highest class of the vertebrates. The manmals furnish milk for their young; they breathe air by means of lungs; they have a four-chambered heart, and a double circulation of the blood; and the thorax and abdomen are separated by a diaphragm. The members of this group vary from the curious duck-bill of Australia to man. 



\section{Science.}

Ballard's World of Matter. A guide to mineralogy and chemistry. \$r.oo.

Benton's Guide to General Chemistry. A manual' for the laboratory. 35 cents.

Boyer's Laboratory Manual in Biology. An elementary guide to the laboratory study of animals ard plants. 80 cents.

Boynton, Morse and Watson's Laboratory Manual in Chemistry. 5o cents.

Chute's Physical Laboratory Manual. A well-balanced course in laboratory physics, re quiring inexpensive apparatus. Illustrated. 80 cents.

Chute's Practical Physics. For high schools and colleges. \$1.12.

Clark's Methods in Microscopy. Detailed descriptions of successful methods. \$1.6o.

Coit's Chemical Aritnmetic. With a short system of analysis. ¿c cents.

Colton's Physiology : Experimental and Descriptive. For high schools and colleges. Illustrated. of r.r2

Colton's Physiolo: y: Briefer Course. I or earlier years in high schools. Illustrated. 90 cents.

Colton's Practical Zoology. Gives careful study to typical animals. 60 cents.

Grabfield and Burns's Chemical Problems. For review and drill. Paper. 25 cents.

Hyatt's Insecta. A practical manual for students and teachers. Illustrated. \$r.25.

Newell's Experimental Chemistry. A modern text-book in chemistry for high schools and colleges. \$r.ro.

Orndorff's Laboratory Manual. Contains directions for a course of experiments in Organic Chemistry, arranged to accompany Remsen's Chemistry. Boards. 35 cents.

Pepoon, Mitchell and Maxwell's Plant Life. A laboratory guide. 5o cents.

Remsen's Organic Chemistry. An introduction to the study of the compounds of carbon. For students of the pure science, or its application to arts. \$1.20.

Roberts's Stereo-Chemistry. Its development and present aspects. I.00.

Sanford's Experimental Psychology. Part I. Sensation and Perception. \$r.5o.

Shaler's First Book in Geology. Cloth, 60 cents. Boards, 45 cents.

Shepard's Inorganic Chemistry. Descriptive and qualitative; experimental and inductive ; leads the student to observe and think. For high schools and colleges. \$1.r2.

shepard's Briefer Course in Chemistry, with chapter on Organic Chemistry. For schools giving a half year or less to the subject, and schools limited in laboratory facilities. 80 cents.

Shepard's Laboratory Note-Book. Blanks for experiments; tables for the reactions of metallic salts. Can be used with any chemistry. Boards. 35 cents.

Spalding's Botany. Practical exercises in the study of plants. 80 cents.

Stevens's Chemistry Note-Book. Laboratory sheets and covers. 50 cents.

Venable's Short History of Chemistry. For students and the general reade: $\$ \mathbf{x} .00$

Walter, Whitney and Lucas's Animal Life. A laboratory guide. 50 cents.

Whiting's Physical Measurement. I. Density, Heat, Light. and Sound. II. Dynamics, Magnetism, Electricity. III. Principles and Methods of Physical Measurement, Physical Laws and Principles, and Tables. Parts I-IV, in one volume, $\$ 3.75$.

Whiting's Mathematical and Physical Tables. Paper. 5o cents.

Williams's Modern Petrography. Paper. 25 cents.

For elementary works see our list of

books in Elementary Science.

D.C. HEATH \& CO., Publishers, Boston, New York, Chicago 


\section{Mathematics}

Barton's Theory of Equations. A treatise for college classes. \$r.50.

Bowser's Academic Algebra. For secondary schools. \$1.12.

Bowser's College Algebra. A full treatment of elementary and advanced topics. \$1.50.

Bowser's Plane and Solid Geometry. \$r.25. Plane, bound separately. $75 \mathrm{cts}$.

Bowser's Elements of Plane and Spherical Trigonometry. $90 \mathrm{cts}$; with tables, $\$ 1.40$. bowser's Treatise on Plane and Spherical Trigonometry. An advanced work for cor leges and technical schools. \$r.5o.

Bowser's Five-Place Logarithmic Tables. $50 \mathrm{cts.}$

Fine's Number System in Algebra. Theoretical and historical. \$r.oo.

Gilbert's Algebra Lessons. Three numbers: No. I, to Fractional Equations; No. 2. through Quadratic Equations; No. 3, Higher Algebra. Each number, per dozen, \$r.44.

Hopkins's Plane Geometry. Follows the inductive method. $75 \mathrm{cts}$.

Howland's Elements of the Conic Sections. $75 \mathrm{cts}$.

Lefevre's Number and its Algebra. Introductory to college courses in algebra. \$r.25.

Lyman's Geometry Exercises. Supplementary work for drill. Per dozen, \$r.6o.

McCurdy's Exercise Book in Algebra. A thorough drill book. 6o cts.

Miller's Plane and Spherical Trigonometry. For colleges and technical schools. \$r.15. With six-place tables, \$r.40.

Nichol's Analytic Geometry. A treatise for college courses. \$r.25.

Nichols's Calculus. Differential and Integral. \$2.0o.

Osborne's Differential and Integral Calculus. \$2.00.

Peterson and Baldwin's Problems in Algebra. For texts and reviews. 30 cts.

Robbins's Surveying and Navigation. A brief and practical treatise. 50 cts.

Schwatt's Geometrical Treatment of Curves. \$r.oo.

Waldo's Descriptive Geometry. A large number of problems systematically arranged and with suggestions. $80 \mathrm{cts}$.

Wells's Academic Arithmetic. With or without answers. \$1.00.

Wells's Essentials of Algebra. For secondary schools. \$r.ro.

Wells's Academic Algebra. With or without answers. \$1.08.

Wells's New Higher Algebra. For schools and colleges. \$1.32.

Wells's Higher Algebra. \$1.32.

Wells's University Algebra. Octavo. \$r.50.

Wells's College Algebra. \$1.50. Part II, beginning with quadratics. \$1.32.

Wells's Essentials of Geometry. (1899.) \$r.25. Plane, 75 cts. Solid, 75 cts.

Wells's Elements of Geometry. Revised. (r894.) \$1.25. Plane, 75 cts.; Solid, 75 cts.

Wells's New Plane and Spherical Trigonometry. For colleges and technical schools.

$\$ 1.00$. With six place tables, \$r.25. With Robbins's Surveying and Navigation, \$r.50.

Wells's Complete Trigonometry. Plane and Spherical. go cts. With tables, $\$ 1.08$.

Plane, bound separately, $75 \mathrm{cts}$.

Wells's New Six-Place Logarithmic Tables. 6o cts.

Wells's Four-Place Tables. 25 cts.

For Arithmetics see our list of books in Elementary Mathematics.

D. C. HEATH \& CO., Publishers, Boston, New York, Chicago 

SEP 261902

I COPY DEL, TO CAT. DIV.

SEP. 261902

SFP 30 19n? 





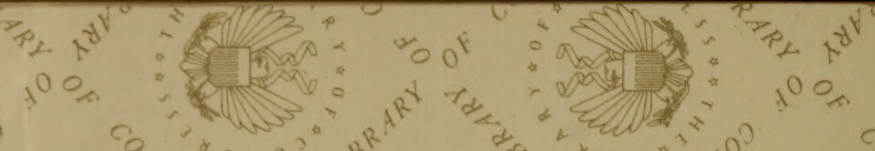
然

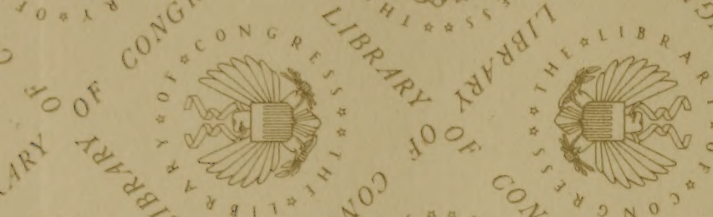

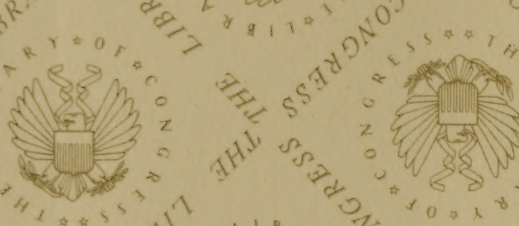

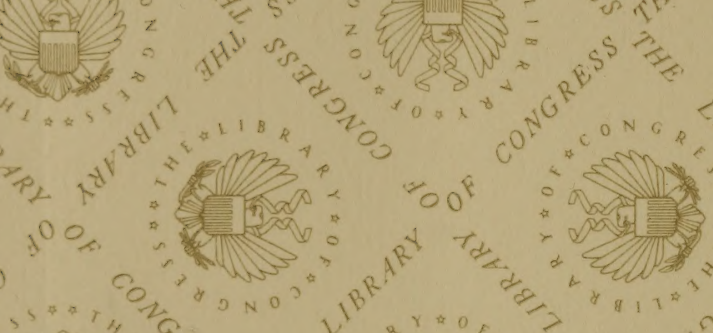

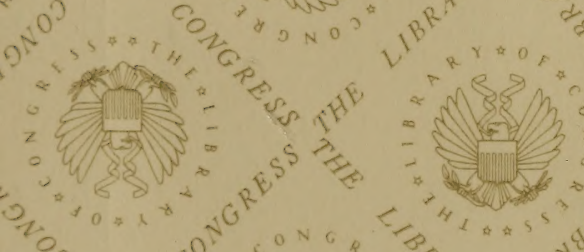

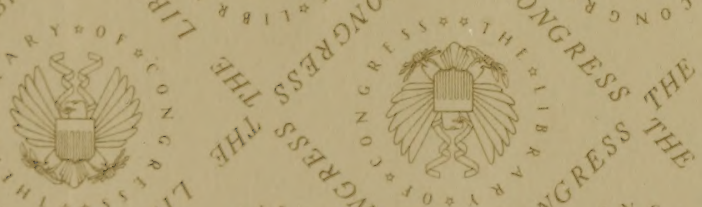

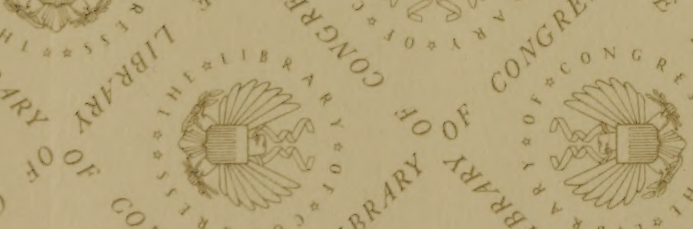

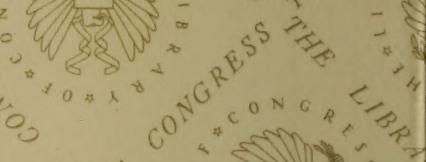




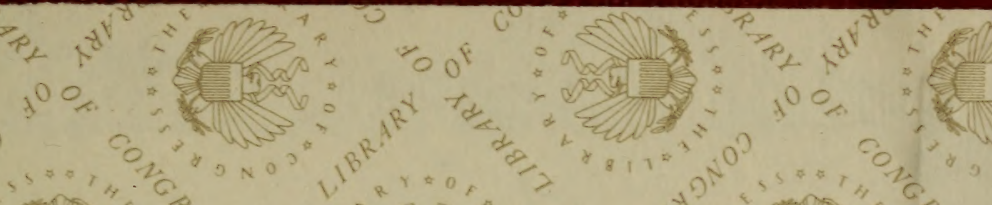

(15)

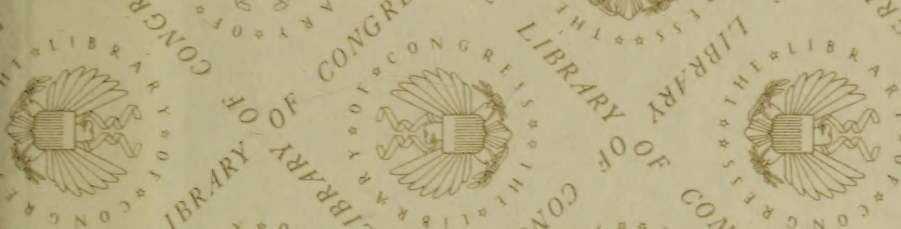

and

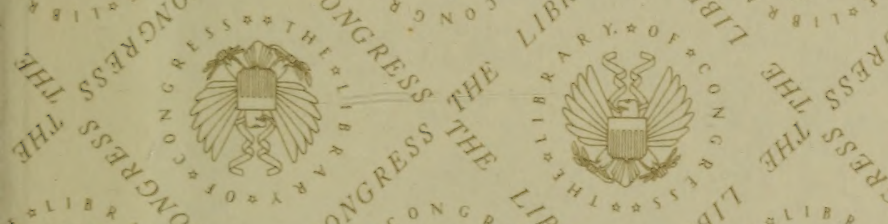

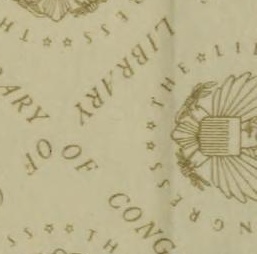
ans

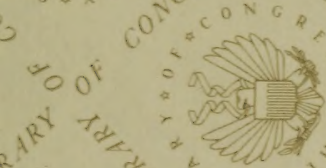

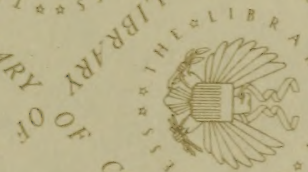

$\sin ^{4}$

a d 
LIBRARY OF CONGRESS

00053927713 